\title{
1 Thaumatin-like proteins: Molecular characterization, evolutionary analysis and expression profiling in major cereal crops
}

3 Alok Sharma ${ }^{1}$, Himanshu Sharma ${ }^{1,2}$ and Santosh Kumar Upadhyay ${ }^{* 1}$

4 1. Department of Botany, Panjab University, Chandigarh, India-160014

5 2. I.K. Gujral Punjab Technical University, Kapurthala, Jalandhar, India-144603

$6 *$ Corresponding Author

7 *Corresponding Author: Dr. Santosh Kumar Upadhyay, Department of Botany, Panjab

8 University, Chandigarh, India-160014. Email: skupadhyay@pu.ac.in, Tel: +91-172-2534001,

9 Fax: +91-172-2779510 


\section{Abstract}

\section{Background}

13 PR superfamily, pathogenesis related (PR) proteins divided into P1-PR17 subfamilies, is 14 involved in the defense mechanism of plants. Thaumatin-like proteins (TLPs) are part of PR-5

15 family that facilitates resistance against abiotic and biotic stress responses.

\section{Results}

17 In the present study, a total of 26, 27, 39, 93 and 37 TLPs with conserved signature-motif were 18 identified in Brachypodium distachyon, Oryza sativa, Sorghum bicolor, Triticum 19 aestivum and Zea mays, respectively. They were phylogenetically divided into 10 different 20 clades. Majority of genes possessed one to three exons. Physicochemical analysis suggested

21 significant differences between small and long TLPs. Majority consisted of signal peptide and 22 localized in extracellular region. Evolutionary analyses suggested the role of duplication events 23 in the expansion of this gene family. Tissue-specific expression of certain genes suggested their 24 role in development, while differential expression revealed their putative roles in stress-response. 25 The occurrence of assorted set of cis-regulatory elements further suggested their diverse 26 functions. Co-expression analysis depicted their interaction with several stress responsive genes.

\section{Conclusions}

28 The detailed characterization of TLP proteins in cereals depicted their importance in combating 29 various biotic and abiotic challenges. This study would be useful in further characterization of 30 individual TLP genes in each plant, and various crop improvement programs in future studies.

32 Keywords: Abiotic stress, Biotic stress, Expression, Thaumatin-like proteins, Triticum aestivum 


\section{Introduction}

Plants have been facing numerous challenges over the course of evolutionary period. Various features have been acquired by plants to tackle the challenging conditions such as climatic change, pathogenic attacks, tissue injury, salinity etc. Growth and development of plants are strongly affected by such stress conditions. Stress conditions including abiotic such as heat, drought, salinity, cold etc. On the other hand, biotic stresses are caused by living organisms such as bacteria, fungi, nematode etc. Plants are adapting and gaining ways of mechanisms to restrain these stress causing agents. For example, production of phytoalexins, proline, sugars, late embryogenesis abundant (LEA) proteins, Pathogenesis related (PR) proteins etc. [1, 2].

PR proteins are a superfamily of defense related proteins named due to their involvement in pathogen stress responses. PR proteins superfamily includes PR1-PR17 sub families, classified on the basis of their different roles and mechanisms [3].

PR5, also known as thaumatin-like proteins (TLPs) family, is one of the important classes of PR superfamily [3, 4]. These proteins were nomenclatured as TLPs due to their significant similarity with a $\sim 23 \mathrm{kDa}$ sweet-tasting protein known as thaumatin [5]. Thaumatin protein was first isolated from an African shrub known as Thaumatococcus danielli [6]. Over the period of time, TLPs have been reported in a diverse group of organisms including insects, nematodes, fungi and plants [7-13].

In plants, TLPs are found to be present in algae, bryophytes, gymnosperm, and angiosperm [1215]. The TLP proteins are grouped into two different forms, long TLPs and small TLPs, based on their molecular weight (MW). Unlike to the cosmopolitan nature of long TLPs, the small TLPs were found to be confined in gymnosperm and monocots only [12, 15, 16]. Furthermore, the long TLPs have a molecular weight of $\sim 21-26 \mathrm{kDa}$, while Small TLPs have MW of $\sim 16-17 \mathrm{kDa}$. A total of 16 and 10 conserved cysteine residues are present in long and Small TLPs, respectively. These cysteine residues form eight disulfide linkages in L-type and five disulfide linkages in S-type TLPs. These disulfide bonds provide resistance to TLPs against extreme $\mathrm{pH}$, heat and protease degradation $[17,18]$. Moreover, structural properties revealed that TLPs have a conserved REDDD motif and a thaumatin signature motif G-X-[GF]-X-C-X-T- [GA]-D-C-X$(1,2)-G-X-(2,3)-C$. The REDDD motif is known to be involved in receptor binding for their antifungal action [12, 19]. TLPs are known for their diverse roles in abiotic and biotic stress tolerance in plants. Various research groups have reported that overexpression of TLPs increases 
resistance against various fungus in both dicot and monocot plants including tobacco, soybean, potato, grapes, rice, wheat etc. [20-25]. The mechanism of TLPs in fungal resistance is ambiguous; however, these are assumed to work by degradation and permeabilization of the fungal cell walls $[26,27]$. In addition, TLPs are known to be involved in antifreeze action and abiotic stress resistance in plants [21, 28-30]. Furthermore, TLPs are reported to be involved in flowering, fruit ripening and seed germination [31-33].

TLP is an important gene family because of its diverse roles in plant development and defense mechanisms. A detailed genome-wide analysis in crops including B. distachyon, S. bicolor and T. aestivum has not been carried out till date. Furthermore, a detailed cis-regulatory, physicochemical, expression and coexpression analysis of TLPs in O. sativa and Z. mays has been carried out in this study, in addition to the previous work [13]. In the present study, we have performed the comprehensive genomic analysis of the TLP protein family in five crops including B. distachyon, O. sativa, S. bicolor, T. aestivum and Z. mays. TLPs were studied in detail to explore their chromosomal distribution, phylogeny, physicochemical properties, gene duplication events, cis-regulatory elements and structural configuration. Moreover, to decipher their putative roles in plant development and under abiotic and biotic stresses, their expression and coexpression analysis was performed using high throughput RNA-seq data. The study will enhance the knowledge about the TLP protein family in five studied cereals. It will shed light on the putative roles of TLPs in various stress and developmental processes, which eventually provides a base for detailed functional studies and various crop improvement programs.

\section{Results}

\section{Identification and Chromosomal localization of TLP genes}

An extensive genomic search of the TLPs in B. distachyon, O. sativa, S. bicolor, T. aestivum and Z. mays resulted in the identification of 26, 27, 39, 93 and 37 TLP genes, respectively. All of the identified genes were having a complete thaumatin signature motif (Additional file 1: Table S1). The genes lacking or having incomplete thaumatin signature motifs were excluded from the study. In this study, four TLPS were identified as small TLPs (sTLPs) in each B. distachyon, O. sativa and Z. mays. A total of 10 and 20 genes were categorized into sTLPS in S. bicolor and T. aestivum, respectively (Additional file 1: Table S1). 
The chromosomal localization analysis suggested the scattered distribution pattern of TLPs on most of the chromosomes of the respective crops (Fig. 1). In B. distachyon, O. sativa, S. bicolor, T. aestivum and Z. mays, TLP genes were localized on 5/5, 11/12, 9/10, 21/21 and 9/10 long and small TLPS), while chromosome numbers 12, 8, and 1 were having the highest number of TLPs in O. sativa, S. bicolor and Z. mays, which were 6, 11 and 13, respectively. In case of $T$. aestivum, the maximum number of TLPS (i.e. 13) were present on chromosome number 5A, while the location of two genes were unknown. Unlike long TLP genes, sTLPs were localized specifically on chromosome numbers 12,8 and 1 in $O$. sativa, S. bicolor and Z. mays, respectively. In $B$. distachyon, sTLPs were specifically present on chromosome numbers 1 and 4; however, sTLPs in T. aestivum were observed on all the chromosomes except chromosome number 1 .

The nomenclatures of TLP genes in B. distachyon, O. sativa, S. bicolor and Z. mays were allotted on the basis of their specific location on their respective chromosomes. In case of T. aestivum, homeologous grouping resulted in 32 homeologous groups, which were named according to the procedure described in methods.

\section{Multiple sequence alignments and tertiary structure of TLPs}

TLPs have various characteristic and conserved residues, which are important for their functional activities. To explore these conserved regions and their similarity with thaumatin protein (P02883.2|THM1_THADA), TLPs of these five cereals along with thaumatin protein were aligned and studied (Fig. 2; Additional file 2: Figure S1). It was found that most of the long TLPs have 16, while all the small TLPs possessed 10 conserved cysteine residues in all the five crops. In addition, 7-5 cysteine residues were predicted in some of the TLPs from $O$. sativa, $S$. bicolor, T. aestivum and Z. mays. REDDD motif residues were conserved in most of the TLPs; however, some of these residues were replaced by amino acids with equivalent or different properties in a few TLPs. Thaumatin signature motif is a characteristic feature of thaumatin-like proteins, which was well conserved in these TLPs. Some other regions like FF hydrophobic 125 TLPs. 
55

A comparative study of the structural configuration of one representative of each small TaTLPs (TaTLP6-A) and long TaTLPs (TaTLP2-A) was carried out in the context of their secondary and tertiary structures. Secondary structure analysis predicted the highest percentage of coil region followed by $\beta$ strands and $\alpha$ helices in both long and small TLPs. The tertiary structure revealed the three complete domains (I-III) in the long TLP, while small TLP protein was lacking a major region of domain II (Fig. 3a, b). In TaTLP2-A, domain I was comprised of $9 \beta$ strands and was the largest one. Further, Domain II was mainly consisted of three small and a large $\alpha$ helix structure, while the domain III was the smallest one and constituted of two $\beta$ strands and a long loop region. In case of TaTLP6-A, sTLP, domain II was comprised of only two $\alpha$ helices, while domain I and III configuration were found similar in both small and long TLP. The cysteine residues were conserved in both small and long TLP proteins. Moreover, eight and five disulfide bonds were present in TaTLP2-A and TaTLP6-A, respectively. Furthermore, the bioinformaticsbased ligand prediction showed iodine, $\beta$-D glucose, dipicolinic acid, ascorbic acids, and mesotartaric acid as probable ligands for both TaTLPs.

\section{Phylogenetic analysis}

To decipher the evolutionary relationship of the TLP family among five cereals and $A$. thaliana, a phylogenetic tree was built using full-length peptide sequences. These TLPs were clustered into 10 different clades based on their phylogenetic relatedness, named as groups I to X (Fig. 4). The highest number of TLPs were found in group $\mathrm{X}$ followed by group II, while group IV was smallest with only five genes. Interestingly, all the sTLPs were specific to group X only. Furthermore, it was observed that groups I, II, VII, VIII and IX consisted of TLPs from all the five cereals, while Group III, V and VI lack the members of one or more plant species. However, group IV was composed of only three TaTLP and two AtTLP proteins. Additionally, it was found that, with few exceptions, most of the TLPs of Group I, III, IV, IX and X were with 3, 1, 3, 2 and 1 exons, respectively. Moreover, the ranges of exon varied from 1-3, 2-3, 2-11, 2-4 and 1-4 in groups II, V, VI, VII and VIII, respectively. The homeologous TLPS of T. aestivum were found together in close proximity. 


\section{Duplication events investigation}

We have performed the duplication event (DE) analysis of TLPS of all five crops. DEs were studied to understand their roles in the evolution and expansion of TLP gene family. A total of one, four, three, six and eight DEs were found in B. distachyon, O. sativa, S. bicolor, T. aestivum and $Z$ mays (Fig. 1; Additional file 3: Table S2). All the paralogous genes in B. distachyon (BdTLP1-BdTLP2), O. sativa (OsTLP5-OsTLP7, OsTLP22-OsTLP24, OsTLP23-OsTLP25, OsTLP26-OsTLP27) and S. bicolor (SbTLP28-SbTLP29, SbTLP31-SbTLP34, SbTLP32SbTLP33) were due to the tandem duplication events. In the case of $T$. aestivum, five out of six DEs were segmental (TaTLP1-A-TaTLP24-D, TaTLP1-B-TaTLP24-B, TaTLP12-B-TaTLP13-D, TaTLP15-A-TaTLP18-B, TaTLP15-B2-TaTLP18-A) and one was tandem DE (TaTLP16-ATaTLP17-A). In Z. mays, seven segmental (ZmTLP1-ZmTLP35, ZmTLP2-ZmTLP34, ZmTLP3ZmTLP22, ZmTLP9-ZmTLP12, ZmTLP13-ZmTLP37, ZmTLP16-ZmTLP33, ZmTLP20ZmTLP25) and one tandem (ZmTLP6-ZmTLP7) DEs were found. In the context of paralogous genes, it was observed that all the duplicated gene pairs of each cereal crop were tightly clustered in the same clade, for instance, BdTLP1 and BdTLP2, OsTLP5 and OsTLP7, SbTLP28 and SbTLP29, TaTLP1-B and TaTLP24-B, ZmTLP16 and ZmTLP33.

\section{$\mathrm{Ka} / \mathrm{Ks}$ and Tajima's relative rate test}

Over the course of evolution, various evolutionary forces and natural pressures affect the duplicated genes [34]. To understand the evolutionary divergence between the paralogous gene pairs of these five cereals, we carried out the $\mathrm{Ka} / \mathrm{Ks}$ analysis. The value of more than one and less than one of $\mathrm{Ka} / \mathrm{Ks}$ ratio suggests the positive (Purifying) and negative (non-purifying) selection pressure, respectively. All the paralogous genes showed the $\mathrm{Ka} / \mathrm{Ks}$ value lesser than one, which suggested the negative or purifying selection on TLP duplicated genes (Table 1). However, Ka/Ks analysis for ZmTLP6 and ZmTLP7 was not performed due to their $100 \%$ similarity. Additionally, the divergence time of DEs was also calculated using the Ks value and previously described methods $[35,36]$. The divergence time of duplicated genes was calculated as 83 million years ago (MYA) in BdTLPs, while the range varied from 52-108, 6-137, 63-99 and 1-63 MYA in O. sativa, S. bicolor, T. aestivum and Z. mays, respectively (Table 1). 
186

187

188

189

190

191

192

193

194

195

196

197

198

199

200

201

202

203

204

205

206

207

208

209

210

211

\section{Physicochemical properties}

213 To understand their several important features, analysis of several physicochemical properties of

214

215

216

The Tajima's relative rate test found the insignificant $\chi 2$ value for all the duplicated gene pairs at $\mathrm{P}>0.05$ (Table 2). The $\mathrm{P}$ value of more than 0.05 depicted their acceptance of the molecular evolutionary clock hypothesis [37].

\section{Gene architecture, domain and motif analyses}

Gene structural organization analysis includes exon/intron arrangements and phase distribution in TLPs. The number of exons varied from one to three in O. sativa, while one to four in $B$. distachyon, S. bicolor and T. aestivum. In case of Z. mays, most of the TLPs had a range of one to three exons, while ZmTLP16, ZmTLP20, ZmTLP25 and ZmTLP33 consisted of eleven, seven, eight and ten exons, respectively. A total of 98 out of 222 TLPS of five crops were intronless. Intriguingly, except TaTLP-6A and TaTLP20-A1, all the sTLPs were intronless. Furthermore, the intron phase analysis revealed that the maximum number of introns were in phase 1, followed by phase 2, while the least number of introns were in phase zero (Additional file 4: Figure S2).

Functional nature of a protein depends on the type of domains present in it. All of the TLPs from these five cereals possess a thaumatin domain (PF00314). The average domain sizes of long TLP in B. distachyon, O. sativa, S. bicolor, T. aestivum and Z. mays were approx. 217, 207, 216, 214 and 202 AA, respectively. On the other hand, average thaumatin domain sizes of sTLPs were 154, 151, 147,134 and 148 amino acids (AA) in B. distachyon, O. sativa, S. bicolor, T. aestivum and Z. mays, respectively. In addition to the thaumatin domain, ZmTLP16, ZmTLP20, ZmTLP25 and ZmTLP33 also had a nuclear protein 96 (NUP96) domain. The NUP96 domain of size 211 AA was present on the cytosolic terminal of these proteins (Additional file 5: Table S3).

Motif investigation revealed the 10 most conserved motifs in TLPs. Motifs 1-9 were the parts of the thaumatin domain, while motif 10 was unknown. Furthermore, motifs 5, 6 and 8 were the most conserved in TLP proteins. The thaumatin signature sequence was present in motif 8 (Additional file 4: Figure S2). identified TLPs were studied. TLPs were analyzed for their MW, peptide length, pI, subcellular localization, transmembrane helix and signal peptide (Additional file 6: Table S4). The average peptide lengths of long TLPs were 299, 289, 294, 284 and 334 AA and of small TLPs were 185, 
178, 178, 177 and 175 AA in B. distachyon, O. sativa, S. bicolor, T. aestivum and Z. mays, respectively. The average MW were 30.8, 29.8, 30.0, 29.1 and $35 \mathrm{kDa}$ for long TLPs, while 19.5, 18.1, 18.3, 18.2 and $17.7 \mathrm{kDa}$ for small TLPs in B. distachyon, O. sativa, S. bicolor, T. aestivum and Z. mays, respectively. The average isoelectric points were $6.18,6.95,6.05,6.18$ and 5.89 for long TLPs and 6.82, 6.06, 5.74, 6.17 and 4.90 for sTLPs in B. distachyon, O. sativa, S. bicolor, T. aestivum and Z. mays, respectively (Additional file 6: Table S4). The higher average MW and peptide length of ZmTLPs with respect to other crops were due to the presence of four TLPs (ZmTLP16, ZmTLP20, ZmTLP25 and ZmTLP33) with an additional domain.

Transmembrane (TM) helix analysis predicted the 21/26, 21/27, 29/39, 84/93 and 30/37 TLPs were with no TM region, while 5/26, 5/27, 10/39, 7/93 and 7/37 TLPs consisted of single TM region in B. distachyon, O. sativa, S. bicolor, T. aestivum and Z. mays, respectively. However, OsTLP18, TaTLP4-D and TaTLP5-D were comprised of two TM helices each (Additional file 6: Table S4). The analysis of subcellular localization predicted that most of the TLPs were localized in the extracellular region, while three TLPs from $O$. sativa (OsTLP10, OsTLP15 and OsTLP16) shown nuclear and BdTLP16, TaTLP21-A, ZmTLP20, ZmTLP25 and ZmTLP33 shown plasma membrane localization (Additional file 6: Table S4). Signal peptides were found in 23/26, 21/27, 36/39, 86/93 and 33/37 TLPs of B. distachyon, O. sativa, and Z. mays, respectively (Additional file 6: Table S4). All the sTLPs were devoid of the transmembrane helix, and one signal peptide was predicted in all of them.

\section{Promoter region analyses}

Based on their putative functions, the identified cis-regulatory elements were segregated into four types including growth and development, light, hormone and stress-responsive elements (Additional file 7: Table S5). The promoter regions comprised of a number of growth-related elements including TE2F2NTPCNA, EBOX, RYREPEAT4, RAV1AAT, POLLEN1LEAAT52 etc. In case of light-responsive elements, GT1CONSENSUS, GATA box, GBOXLERBCS, BOXII, IBOXCORE were some common cis-regulatory elements. However, under the hormonal responsive category, DPBFCOREDCD3, ARFAT, ARR1, ERELEE4 and GARE10OSREP1 were abscisic acid, auxin, cytokinin, ethylene and gibberellic acid responsive, respectively. Moreover, various abiotic and biotic stress-responsive elements were also found in most of the 
studied TLPs, for instance, DRE2COREZMRAB17, ASF1, BIHD1, CBFHV, CGG-box, GCCCORE, LTRECOREATCOR15, MYB, MYC, WRKY1, W-box, T/G-box etc.

\section{Expression profiling of TLP genes under different tissues and developmental stages}

Expression analysis of genes is a significant way to understand their involvement in various developmental and physiological processes. TLP genes in plants are known to play roles in various tissues and their development pathways. To decipher the role of TLPS in B. distachyon, O. sativa, S. bicolor, T. aestivum and Z. mays, an expression study was carried out using high throughput RNA-seq data [38-40]. Expression of TLPS was very low, hence we have selected only the genes with FPKM value $\geq 0.2$ in at least one of the tissue developmental stage for further analysis. This filter criterion led to the selection of $23,27,37,84$ and $29 T L P s$ in $B$. distachyon, O. sativa, S. bicolor, T. aestivum and Z. mays, respectively. In each plant species, the genes in heat maps formed the different cluster groups on the basis of their expression patterns (Fig. 5a-e). In case of B. distachyon, the genes were clustered into 1-3 groups. BdTLPs of group 1 were highly expressed in early and emerging inflorescence stages, while BdTLP9, BdTLP12 and $B d T L P 23, B d T L P 28$ were upregulated in endosperm and embryo, respectively. Group 2 genes depicted upregulated expression in plant embryo, which was followed by early and emerging inflorescence tissues. Moreover, group 2 genes showed their varied expression in leaf, pistil, embryo and endosperm tissues. The group 3 genes were maximum upregulated in 10 days after pollination (DAP) of seeds, while BdTLP8 and BdTLP18 showed their upregulated expression in pistil tissue as well (Fig. 5a). In B. distachyon, TLPS showed their expression in all tissues and their stages, which suggested their involvement in vegetative and reproductive growth and development. In O. sativa, TLPS were clustered into five groups (Fig. 5b). All of the group 1 OsTLPs showed upregulated expression in seed except OsTLP27, which showed upregulation in root tissue. The majority of group 2 OsTLPs showed high expression in callus. Group 3 genes showed their maximum expression in the shoot; however, OsTLP14 and OsTLP18 were also upregulated in the early inflorescence. OsTLPs belonging to group 4 showed upregulation in early inflorescence, while OsTLP12 and OsTLP19 were upregulated in carpel tissue as well. The result depicted their roles in tissues including both vegetative and reproductive. In S. bicolor, four groups were formed, in which group 1 genes showed differential expression in root tissues except $S b T L P 8, S b T L P 23$ and $S b T L P 27$, which were expressed highly 
278 in anther tissue. In group 2, most of the genes showed high expression in the pistil, while 279 SbTLP4, SbTLP10 and SbTLP26 were differentially expressed in seed as well. Similarly, SbTLP13, SbTLP17, SbTLP38 and SbTLP39 were shown upregulation in plant embryo. SbTLP17 exhibited upregulated expression in all tissues except leaf and anther. In group 3, half of the genes showed their highest expression in the endosperm, while another half showed in flower. In case of group 4, the maximum genes were showing differential expression in leaf (Fig. 5c). In $Z$. mays, genes were clustered into four different groups (Fig. 5e). Most of the genes of group 1 showed significant expression in all stages of tissue development; however, half of the genes were seen to be significantly upregulated in unpollinated silk while the other halves were expressing in pericarp and aleurone layer. Majority of group 2 genes were specifically upregulated to root tissues, while some genes also showed upregulation in internode tissue, namely ZmTLP17, ZmTLP19 and ZmTLP28. Group 3 genes were mostly downregulated but showed significant expression in the embryo. Group 4 genes showed upregulated expression in most of the tissues; however, the maximum expression of these genes observed in leaf followed by internode tissue.

In $T$. aestivum, the genes were high in number and were clustered into four large groups (Fig. 5d). Group 1 was the largest group and most of the genes showed differential expression in root tissue followed by shoot. In addition, genes like TaTLP29-A, B, D and TaTLP4-D showed their upregulated expression in spike tissue as well. Group 2 genes showed highest upregulation in spike and grain; however, some genes such as TaTLP2-D1 and TaTLP1-A also showed varied expression in root tissue. In group 3, most of the genes exhibited upregulated expression in grain, while TaTLP3-A, U, TaTLP13-D, TaTLP32-A, B, and $D$ were highly expressing in leaf, followed by root. Group 4 TaTLPS were expressing higher in grain, while TaTLP7-A, B, D and TaTLP30$A$ were also upregulated in spike. Overall TaTLPS were highly expressed in root, stem and grain tissues, while some genes were also upregulated in spike and leaf.

\section{Expression profiling of TaTLP genes under biotic and abiotic stress conditions}

TLPs belong to defense-related protein family and are well known for their stress-responsive behavior. The expression analysis of TaTLP genes using RNA-seq data was performed under various biotic and abiotic stress conditions to understand their roles in stress resistance [41-43]. 
fungal pathogens, namely, Blumeria graminis f. sp. tritici (Bgt) and Puccinia striiformis f. sp. tritici (Pst) was used for expression pattern analysis [41]. These fungal pathogens are causing agent of powdery mildew and stripe rust diseases, respectively. In T. aestivum, a total of 50 genes were analyzed because of their differential expression in these stress conditions and clustered into four different groups based on their expression pattern (Fig. 6a). In group 1, most of the genes were expressed highly in Bgt infection, while these genes were downregulated or showed mild expression after Pst infestation. However, TaTLP23-A was upregulated in all the conditions. In groups 2 and 3, most of the genes were low expressing and showed their expression mainly in Pst infection. However, TaTLP27-D showed upregulation under both Bgt and Pst infection. The group 4 genes were upregulated at the 24 days after Pst infestation. In Bgt infection, TaTLP3-A2, TaTLP12-A, TaTLP32-A were most differentially upregulated genes with 37, 36 and 35 folds, respectively. However, in comparison to Bgt infection, under Pst infection, a small number of genes, for instance, TaTLP10-A (51 fold up), TaTLP27-D (17 fold up) etc. showed upregulated expression.

Abiotic stresses are another major threat to plants, which affect the various physiological and biological processes of plants. To understand the putative role of TaTLPS in abiotic stress conditions, expression analysis was carried out under drought (DS), heat (HS) and combined stress of heat and drought (HD) stress using online available RNA-seq data [42]. A total of 52 TaTLPs were analyzed which formed four different clusters in the heatmap (Fig. 6b). Most of the genes in group 1 were downregulated in DS, HS and HD stresses. However, TaTLP15-B3 and TaTLP27-B exhibited significantly upregulated expression under HS and HD. In group 2, only three genes namely, TaTLP5-D, TaTLP9-A and TaTLP9-D were highly expressing in all three stresses. Most of the TaTLPS from group 3 exhibited higher expression at $6 \mathrm{~h}$ of DS, while few genes of group 3 such as TaTLP14-A1, B1, TaTLP25-D etc., showed differential expression in all the stress conditions. In group 4, TaTLP7-D showed upregulated expression at $1 \mathrm{~h}$ of HS and HD stress, while TaTLP28-A was upregulated at both 1 and $6 \mathrm{~h}$ after HS treatment.

Expression analysis of TaTLPs under salt stress was done using online available RNA-seq data [43]. Out of 93 genes, 63 genes were found to be differentially expressing and used for further expression analysis. These 63 genes were clustered into 4 groups, based on their expression patterns (Fig. 6c). In group 1, genes were downregulated in all the salt treatment conditions, while group 2 genes showed similar expression as control conditions. However, TaTLP2-B 
exhibited 6 fold upregulated expression in initial hours of salt treatment. In group 3, TaTLPS exhibited upregulated expression at 24 and $48 \mathrm{~h}$ of salt treatment. Precisely, TaTLP3-U, TaTLP14-B1 and B5 showed upregulated expression at all the time intervals of salt stress with most 18, 9 and 10 fold up change at salt 48 h, respectively. Group 4 genes were upregulated at 12 and $24 \mathrm{~h}$ and showed downregulation at $48 \mathrm{~h}$ of salt treatment.

\section{Co-expression networking of TLPS}

To understand the interacting network of $T L P$ genes, a co-expression study was carried out under various tissue developmental stages of each studied cereal (Fig. 7a-e). Additionally, in $T$. aestivum, the co-expression study was also performed under a biotic and abiotic stress conditions (Fig. 8a-c). In B. distachyon, a total of 64 transcripts were co-expressing with three BdTLP genes. Out of these three genes, BdTLP17 exhibited co-expression with maximum 51 transcripts. These co-expressed gene encode hydrolases, chitinases, kinases, defense-related, DNA binding, etc. proteins (Fig. 7a; Additional file 8: Table S6). In the case of O. sativa, seven OsTLPs were co-expressed with a total of 101 transcripts. OsTLP4 and OSTLP1 exhibited co-expression with 29 and 25 transcripts, respectively. Various proteins, for instance, PR-1, hydrolases, ion binding, proteases, kinases etc. were encoded by these co-expressed transcripts (Fig. 7b; Additional file 8: Table S6). In the $S$. bicolor, nine $S b T L P$ s showed co-expression with a total of 137 transcripts. SbTLP15, SbTLP36 and SbTLP5 showed maximum co-expression with 38, 32 and 29 transcripts, respectively. Co-expressed transcripts included various proteins responsible for ion binding, protein degradation, stress-related, development-related etc. (Fig. 7c; Additional file 8: Table S6). In Z. mays, a total of four ZmTLPs exhibited co-expression with 97 transcripts. The ZmTLP29 showed co-expression with 68 transcripts encoding responsive proteins for drought, hormone, oxidative stress, biotic stress etc. (Fig. 7e; Additional file 8: Table S6).

In case of $T$. aestivum, under tissue and developmental stages, a total of 10 TaTLPs revealed their co-expression with 121 transcripts. Most co-expressed genes were TaTLP31-B and TaTLP20-A6 with 53 and 51 transcripts, respectively. These co-expressed transcripts translate different proteins, like the transporter, kinase, ATP synthase, ethylene-responsive etc. (Fig. 7d; Additional file 8: Table S6). However, under biotic stress, most of the co-expressed genes were interacted with TaTLP18-B and these interacted genes encode proteins related to signaling, transport, DNA repair, disease resistance pathways (Fig. 8a; Additional file 9: Table S7). 
371 Moreover, in case of HD and salt, 15 and 35 TaTLPs were co-expressed with 109 and 102

372 transcripts, respectively. However, TaTLP14-B5 and TaTLP10-A exhibited co-expression with

373 most of the transcripts in HD and salt stress, respectively. Annotation revealed that co-expressed

374 transcripts encode various proteins for stress-resistant, hormone-responsive, kinase, transporters

375 etc. (Fig. 8b, c; Additional file 9: Table S7). Furthermore, gene ontology study of co-expressed

376 transcripts also predicted their involvement in antifungal response (GO:0009817), antibacterial

377 stress response (GO:0042742), drought stress response (GO:0009414), salt stress response

378 (GO:0005634), oxidative stress response (GO:0006979), signaling transduction (GO:0007165),

379 calcium ion transport activity (GO:0070588), metal ion binding activity (GO:0046872),

380 hydrolase activity (GO:0016787), peroxidase activity (GO:0005777), plant development

381 (GO:0009960) etc.

382

383

Comparative expression profiling of TaTLP paralogous genes

384 To understand the functional relationship between the paralogous genes, a comparative 385 expression profiling of each paralogue pair was done. Generally, on the basis of their expression 386 pattern, duplicated genes could categorize into three different types; retention of function, pseudo-functionalization and neo-functionalization. Out of six paralogous genes, three pairs including TaTLP1-A-TaTLP24-D, TaTLP1-B-TaTLP24-B, TaTLP15-A-TaTLP18-B showed a similar trend of expression, which suggested these as retention of function type (Fig. 9a-c). However, two duplicated pairs of TaTLPs (TaTLP12-D-TaTLP13-D, TaTLP16-A-TaTLP17-A) had insignificant expression in one of the gene under most of the tissues, which kept these pairs under pseudo-functional category (Fig. 9d, e). TaTLP15-B2 and TaTLP18-A lack the expression data in most of the tissue; therefore, they were excluded for comparative analysis. Maximum number of retention of function type and lack of neo-functionalization kind suggested the conserved nature of TLPS during the evolution.

\section{Discussion}

398 TLPs are member of defense proteins and these are known to play pivotal roles in both abiotic 399 and biotic stresses [44-46]. Moreover, these proteins are also found to be involved in plant 400 development [31-33]. Therefore, we have studied TLPs in five major cereals including $B$. 401 distachyon, O. sativa, S. bicolor, T. aestivum and Z. mays. In the present study, we have 
402

403

404

405

406

407

408

409

410

411

412

413

414

415

416

417

418

419

420

421

422

423

424

425

426

427

428

429

430

431

432

identified a total of 26, 27, 39, 93 and 37 TLPs in the genome of B. distachyon, $O$. sativa, S. bicolor, T. aestivum and Z. mays, respectively. Previous studies reporting different numbers of TLPs in Arabidopsis (24), false brome (26), field mustard (20), grape (33), poplar (49), rice (49), sorghum (36), maize (49), moss (6) and white pine (10) [13-15, 47-49] suggests the presence of a varied number of TLPs in different plants. The higher number of TLPs in T. aestivum as compare to other species might be attributed to their complex allohexaploid genome configuration (AABBDD) [50]. Furthermore, the different extent of expansion of TLPs among different plant species might be attributed to the number of duplication events. The duplication events are responsible for the expansion of gene families and these are the major forces to attain neo functionality by causing genetic variability [51-53]. In DEs analysis, our results suggested that tandem DEs are a major factor in B. distachyon, $O$. sativa and $S$. bicolor and segmental DEs in $T$. aestivum and Z. mays behind the gene expansion of TLP family. The higher number of paralogous genes in T. aestivum and Z. mays might be attributed to their larger genome size and the presence of more transposable elements [53, 54]. In the year 2016, Cao et al., also found the role of tandem and segmental types of duplication in the evolution of TLP gene family in Arabidopsis, rice, poplar, and maize [13]. Furthermore, the divergence time of monocots from eudicots was estimated as $\sim 170-235$ Mya, which were further diverged into grasses before $\sim 77$ Mya [54, 55]. Time calculation of paralogous gene formation in B. distachyon in our study showed the occurrence of DE before the divergence of grasses. The main duplication incidence in S. bicolor and O. sativa genome was estimated around $\sim 70$ Mya [56]. Most of the paralogous TLPS of $O$. sativa and S. bicolor suggested their formation after the main DE occurrence, while few pair showed their emergence before the grass divergence during the analysis. In Z. mays, paralogous genes depicted their time of occurrence near to divergence time of maize from sorghum which was predicted to be around 11-28 Mya [56]. However, two duplicated pairs, having NUP 96 domain showed their recent incidence of DEs. In T. aestivum, paralogous genes showed their occurrence much earlier than hybridization event of A, B and D sub genome [50]. Duplicated genes face various environmental forces and natural pressures during the process of evolution [34]. In our study, all the paralogous gene pairs showed purifying selection as a major force of selection. The similar results were found in the evolutionary study of six plant species and melon in which purifying selection of TLPS was reported, while the positive selection was experienced by only few amino acid residues $[13,57]$. However, in poplar, positive selection was 
433 also experienced in $10 T L P s$, which suggested the varied natural selection procedure in TLPs' 434 evolution [14]. Furthermore, Tajima's relative test found the equal rate of evolution in paralogous genes, which again suggested the conserved nature of TLP genes.

436 TLPs were found to be paraphyletic in nature and were supposed to be originated from 10 437 ancestral genes [11]. Similarly, in our study, phylogenetic analysis showed the clustering of 438 TLPs in 10 different clades. The uneven pattern of genes in different clades was observed, where maximum genes were present in the group number 10. The high number of paralogous genes in group 10 suggested a higher rate of expansion in this group. However, specific plant TLPs in some groups suggested the species-specific expansion of these groups. Intron-exon numbers were found to be equal in most of the members of the same clades, while half of the clades showed varied intron-exon numbers amongst them. The intron-less nature of group 10 showed their evolved nature, which was well supported by existence of all the sTLPs exclusively in this group. The similar results with uneven distribution and paraphyletic nature of TLPs have also been reported by previous studies [13, 57]. The close clustering of paralogous genes and homeologous groups further confirmed the grouping of TLPs in the phylogenetic tree. The organization of introns and exons of TLPs have been reported to be in the range of one to ten exons $[12,13,15,49]$. On similar patterns, our results suggest comparable findings with one to four exons in most of the TLPs. However, most of the monocots' TLPs have intron-less nature, which was also found in our analysis [13]. Additionally, our results with respect to the protein lengths, molecular weights and isoelectric points of long and small TLP proteins, found in accordance with previously studied TLPs $[12,13,15]$. Most of the TLPs have N-terminal signal peptides and are localized to the secretory pathways [12, 13]. Similar results in respect to localization and signal peptide were obtained in our study. Furthermore, lack of transmembrane helix in most of the TLPs, confirm their extracellular location and non-membranous nature. In addition, the presence of thaumatin-like domain in all the TLP proteins, make our studies similar to previously reported findings. However, four ZmTLPs (ZmTLP16, ZmTLP20, ZmTLP25, and ZmTLP33) have an additional NUP 96 domain. The function of the NUP 96 domain was found to be involved in plant development and stress resistance against fungal and bacterial pathogens,

462 in all the TLPs, which again suggested their similar functional roles and conservation among 
464

465

466

467

468

469

470

471

472

473

474

475

476

477

478

479

480

481

482

483

484

485

486

487

488

489

490

491

492

493

494

explored with multiple sequence alignment. In multiple sequence alignment, all the 10 and 16 cysteine residues in most of the small and long TLPs were found to be conserved, respectively. The REDDD, FF hydrophobic, thaumatin signature motifs were found to be conserved among most of the TLPs, which suggested their functional and structural conserved nature with previously studied TLPs from different plants [12, 14, 15, 48, 49, 57].

The secondary and tertiary structural modeling of TaTLP2-A and TaTLP6-A provided an overview of the three-domain structural aspects of the TLPs. The three-domain structure of both sTLPs and long TLPs showed significant differences in the domain architecture. Partial presence of domain II in TaTLP6-A might be important; however, it is yet unexplored. Further detailed analysis is required to unveil the impact of the absence of domain II in small TLPs. Conserved disulfide bonds in both representatives of small and long TLPs might be responsible for the structural integrity of the protein. In the year 2008, Ghosh and Chakrabarti reported the involvement of conserved cysteine residues in the structural integrity of TLPs in tomato [17]. Furthermore, a thaumatin-like xylanase inhibitor of T. aestivum, TLX1, has been reported to possess five disulfide bonds and three $\beta$ sheets [16]. In addition, the presence of, three domains pattern, a varied number of $\beta$ sheets, alpha helices, and disulfide bonds have also been reported in tobacco, banana, tomato, grape and sodom apple TLPs [17, 60-63]. More than one ligand was predicted in a bioinformatic based analysis of both TLP proteins. In a study, the binding interactions of TLPs to carbohydrates like (1,3) $\square \beta \square \mathrm{D} \square$ glucans and their role in malting has been reported in barley $[26,64]$. One such predicted ligand, $\beta$-D glucose, may have similar roles in the TaTLPs. The binding of ascorbic acid with TaTLPs suggested their possible roles in oxidative stress tolerance. However, experimental functional analysis is required to explore the possibilities.

Expression pattern of genes is important to depict their functional roles [65]. Expression profiling of TLP genes in five cereals, suggested their involvement in various tissues and their developmental stages. The expression results suggested the divergent expression of TLP genes in various tissues including, root, shoot, leaf, inflorescence, endosperm, embryo etc. This expression pattern depicted their roles in both vegetative and reproductive development. In $T$. aestivum, expression profiling also suggested the divergent expression of TaTLPs in the root, leaf, stem, spike and grain, which depicted their functional involvement in these plant organs. However, the upregulation of some genes under specific tissues hinted towards their role in the 
development of the tissues. Previously, a similar trend of TLP expression was reported in rice [13]. Moreover, TLPs were also found to be involved in fruit ripening, seed germination, and nodule specificity in different plants [33, 66, 67].

The expression studies of TaTLP genes under various abiotic stress conditions such as heat, drought, combined heat and drought and salt stress showed their roles in these stress conditions. In case of DS, most of the TaTLP genes were upregulated in initial hours; however, they showed downregulation afterward. Under HS and HD stress, TaTLPS showed differential expression at later stages of stress treatments. These results suggested the involvement of TaTLPs at different time intervals of these stresses. The salinity stress treatment unveiled the participation of a few TaTLP genes in 48 and 72 hours of salt stress. Our results suggest possible roles of TLPs against different abiotic stress conditions in T. aestivum. In a previous study, the role of TLPS as heat shock protein was suggested in rice [13]. In another study upregulated expression of TLPS at different hours of drought, salt and cold treatment in Brassica rapa was reported [48]. Moreover, over-expression of TLPS was found to increase the resistance against various abiotic stresses in tobacco, cotton, cynanchum, peanut, Arabidopsis etc. [20, 44, 45, 68, 69]. Furthermore, TLPs are well studied with respect to their antifungal properties. Expression profiling of TaTLPs depicted their upregulated expression in response to Bgt and Pst infection. Half of the TaTLPs were highly expressed upon Bgt infestation and showed their downregulated expression in Pst, while other half showed a reverse expression pattern in Bgt and Pst. There are studies, which showed the involvement of PR5 genes or specifically TLPS of T. aestivum in response to fungal attacks. For instance, the induction of TaPR5 by stripe rust and TaLr35PR5 by leaf rust is reported [25, $46,70]$. Furthermore, various other studies also found the role of TLPs to increase the resistance of wheat against Fusarium graminearum [71-73], Microdochium nivale [74] and Stagonospora nodorum [75]. In addition to wheat, some other plants' TLPs have also been reported to be involved against various fungal pathogens, for instance, Alternaria sp. [76, 77], Colletotrichum gloeosporioides [78], Fusarium sp. [79], Podosphaera xanthii [57], Rhizoctonia solani [45, 80], Sclerotinia sclerotiorum [81], Verticillium dahliae [68] etc. The results of expression analysis of studied five cereals suggest the putative roles of TLPS in various abiotic and biotic stress conditions.

Promoter elements are known to be necessary for the regulation of gene expression under different conditions. The presence of cis-regulatory elements responsible for various important 
526 functions suggests the possible involvement of TLPS in different processes. The expression of

$527 T L P$ genes were reported to be regulated by various factors like hormones, wound, pathogens, 528 osmotic stress [5]. The expression profiling of TaTLPs revealed the significant upregulated 529 expression of TaTLP3-A2, TaTLP12-A and TaTLP32-A under biotic stress, which is well 530 supported by the occurrence of various diseases and wound responsive elements such as W-box elements in these genes. Earlier, the involvement of W-box elements in fungal response has been reported in a rice TLP (Rtlp1) [82]. Similarly, the presence of drought, salt and cold (MYB, MYC, DRE2COREZMRAB17, DRECRTCOREAT, LTRECOREATCOR15) responsive elements in TLPs confirm their involvement in abiotic stress tolerance. The promoter sequence analysis has suggested that TLPS might be involved in the defense mechanism as well as the developmental processes of plants.

During co-expression analysis, the majority of TLPS made an interaction network with chitinases, kinases, hydrolases, transporters etc. These co-expressed proteins were earlier found to be involved in disease resistance mechanisms [83-86]. Our study suggests the possible roles of TLPs in signaling, transport, fugal cell wall lysis etc., which was well supported by the earlier findings $[13,87]$. However, to functionally validate the $T L P$ genes in various stress conditions, functional characterization of each candidate gene is needed to be done in future studies.

\section{Conclusions}

545 Thaumatin-like proteins (TLPs), a part of PR5 protein family, are known to be involved in various biotic and abiotic stress conditions. The curiosity to unravel the various possibilities led us to detailed in silico characterization of a total of 222 TLP genes in five cereals. Factors like

548 heat, drought, cold, pathogenic attacks, tissue injury have made a negative impact on the worldwide production of cereals. Here in this study, we have analyzed the physical and chemical characteristics of TLP proteins along with the analyses such as evolutionary, domain structure, transmembrane, cis-regulatory element, multiple sequence alignments, sub-cellular localization, and secondary and tertiary structure analysis. Furthermore, expression analysis has given us strong indications about the important roles of TLPS in combating abiotic and biotic stresses along with playing roles in various plant development stages. The co-expression study has

555 provided us the prediction about the interaction of TLP genes with other stress related genes of respective cereals. The detailed analysis will lay down a path for various crop improvement 
557 programs for important cereals including $T$. aestivum, O. sativa, Z. mays, S. bicolor, B. 558 distachyon.

559

560

561

562

563

564

565

566

567

568

569

570

571

572

573

574

575

576

577

578

579

580

581

582

583

584

585

586

587

\section{Methods}

\section{Identification and nomenclature of $T L P$ genes}

Extensive BLAST searches were used to identify the TLP proteins in five different cereals including B. distachyon, O. sativa, S. bicolor, T. aestivum and Z. mays. Arabidopsis TLP sequences were used as query sequences against the protein model sequences of each crop for separate BLAST searches at Ensembl Plants [15, 87]. Presence of the thaumatin (PF00314) domain was analyzed using Hidden Markov Model (HMM) and Pfam blast searches at e-value $10^{-10}$. Identified TLP sequences were further subjected to NCBI Conserved Domain Database (CDD) BLAST for the confirmation of the presence of the thaumatin domain. In terms of splice variants, only the longest transcripts were selected in each crop. TLP genes with complete thaumatin family signature were selected for further analysis. Furthermore, TLPs having kinase were also removed as they have already been characterized [87]. The sequences of crops were named on the basis of their chromosomal distribution with the exception of T. aestivum. The international rules for gene symbolization of $T$. aestivum (http://wheat.pw.usda.gov/ggpages/wgc/98/Intro.htm) were followed for the nomenclature of TaTLPs.

\section{Chromosomal localization and duplication events}

Plant Ensemble (http://plants.ensembl.org/) was used for gathering the chromosomal and subgenomic location of TLPS of all five crops. Furthermore, homeologous groups in T. aestivum with $\geq 90 \%$ sequence similarity and their presence on the related chromosomes were predicted using the best bidirectional blast hit approach. MapInspect software was used for the mapping of the TLP genes on their respective chromosomes (http://www.plantbreeding.wur .nl/uk/software_mapinspect.html.2012). Duplication events were identified using a bidirectional blast hit approach with sequence similarity $\geq 80 \%$. Duplication events (tandem and segmental) were differentiated on the basis of distance as per the previous studies [88].

\section{Multiple sequence alignments, phylogeny and structural analysis}

Softwares including Muscle and Multalin were used for the multiple sequence alignments of all the TLPs with a thaumatin protein (P02883.2|THM1_THADA) to find the conserved residues 
588 [89, 90]. Evolutionary analysis was done using MEGAX software [91]. Maximum likelihood

589 method with a bootstrap value of 1000 was used to build an evolutionary tree.

590 Selected TLPs from T. aestivum were studied for their secondary and tertiary structure analysis

591 using Iterative Threading ASSEmbly Refinement (I-TASSER) server. The probable ligands and

592 their binding sites were also predicted [92].

$593 \mathrm{Ka} / \mathrm{Ks}$ and Tajima's relativity test

594 The alignment of the protein and nucleotide sequences of the paralogous gene pairs was done

595 using ClustalOmega server (https://www.ebi.ac.uk/Tools/msa/clustalo). Further, the synonymous

596 substitution per synonymous site (Ks) and non-synonymous substitution per non-synonymous

597 site $(\mathrm{Ka})$, and the $\mathrm{Ka} / \mathrm{Ks}$ ratio was calculated using PAL2NAL programme [93]. The calculation

598 of divergence time of each pair of duplicated genes was done using the formula $\mathrm{T}=\mathrm{Ks} / 2 \mathrm{r}$, where

$599 \mathrm{~T}$ represents the divergence time and $\mathrm{r}$ represents the divergence rate. The divergence rate was

600 assumed to be $6.5 \times 10^{-9}$ for cereals [94]. Moreover, Tajima's relativity test was performed to

601 find out the evolutionary rate between paralogous genes [37].

602 Gene structure organization

603 The genomic and CDS sequences of identified TLPS were used for the analysis of gene structure

604 in terms of exon-intron organization and intron phases. GSDS 2.0 server was used to prepare the

605 pictorial display of the exon-intron organization for the sequences of each crop [95].

606 Physicochemical properties of TLPs

607 Various characteristics including peptide length, molecular weight and isoelectric point of each

608 TLP were analyzed using the ExPasy tool, which were further confirmed by Ensemble plants and

609 Sequence Manipulation Suite [96-98]. Moreover, tools including CELLO v.2.5, ngLOC,

610 ProtComp9 and WoLF PSORT were used for the prediction of subcellular localization of TLPs

611 [99-102]. Tools such as Phobius and DAS-Tmfilter were used for the prediction of

612 transmembrane regions in each TLP protein [103, 104]. Further, the signal peptides were

613 detected using the tool Phobius and SignalP [103, 105]. SMART server was used for the domain

614 analysis, whereas, motifs were analyzed using MEME v.4.11.4 [106, 107].

615 Cis-regulatory element analysis

616 To find out the promoters, $15 \mathrm{~kb}$ upstream sequence from initiation codon was selected in

617 genomic sequences of each cereal. These promoter region elements were analyzed using PLACE 
618 software [108]. Furthermore, the cis-regulatory elements were categorized on the basis of their

619 functions.

620

621

622

623

624

625

626

627

628

629

630

631

632

633

634

635

636

637

638

639

640

641

642

643

644

645

646

647

648

\section{Expression profiling}

Expression analysis in various tissues of each crop was done using the high throughput RNA-seq data retrieved from URGI database (wheaturgi.versailles.inra.fr/files/RNASeqWheat/) and Expression ATLAS [38-40]. In T. aestivum, the expression data generated in replicates for various tissue developmental stages, under biotic (fungal pathogen) and abiotic (heat, drought and salt) were used [41-43]. Data generated for three developmental stages of root, stem, leaf, spike and grain was used to analyze the tissue-specific expression in wheat. Further, RNA-seq data (PRJNA243835) generated in triplicates after the 24, 48 and 72 hour (h) of inoculation of Blumeria graminisf. sp. tritici (Bgt) and Puccinia striiformisf. sp.tritici (Pst) in seven days old seedlings was used for the TaTLP expression analysis under biotic stress [41]. Under abiotic stress conditions, duplicate RNA-seq data (SRP045409) for 1 and 6 hours treatments of heat (40 C), drought (20\% PEG 6000) and the combination of both heat and drought stresses was used to study the TaTLP expression [42]. Furthermore, root RNA-seq data (SRP062745) available in triplicates under the treatment of $150 \mathrm{mM} \mathrm{NaCl}$ at $6,12,24$ and 48 treatment were used to analyze the expression of TaTLPS under salt stress [43]. The RNA-seq datasets were further validated using the WheatExp server. Trinity package was used to calculate the expression value in terms of FPKM value [109]. Hierarchical Clustering Explorer 3.5 was used to generate heat maps of differentially expressed genes, which were clustered using Euclidean distance method [110].

\section{Co-expression and interactome analysis}

Whole expression data of each crop were used to perform co-expression analysis of TLPS in all the five cereals [38-40]. In addition, the co-expression analysis of TaTLPs under abiotic and biotic stress was performed using complete expression data of $T$. aestivum. co-expression analyses were done using the software CoExpress v.1.5 with the threshold value $\geq 0.9$, correlation power 1 with 100 bootstraps [111]. Further, Blast2GO software was used for the functional annotation of co-expressed genes. The pictorial representation of interacting genes was made by the tool Gephi 0.9.1 [112].

\section{Abbreviations}

Bgt: Blumeria graminis 
649 PR: Pathogenesis related

650 DS: Drought stress

651 HD: Heat and drought stress

652 HS: Heat stress

653 Pst: Puccinia striiformis

654 STLP: Small thaumatin-like protein

655 Declarations

656 Ethics approval and consent to participate:

657 Not applicable

658 Consent for publication:

659 All the authors have agreed for publication.

660 Availability of data and materials

661 All the analyzed data of this work are included in this manuscript and its additional files. The

662 genomic data used in this study are available at (https://plants.ensembl.org/index.html). The

663 RNA-seq data of $B$. distachyon, $O$. sativa, S. bicolor, Z. mays and T. aestivum is available at

664 Expression ATLAS and URGI database (wheaturgi.versailles.inra.fr/files/RNASeqWheat/). The

665 RNA-seq data used for expression analyses in T. aestivum is online available at NCBI database

666 with accession numbers PRJNA243845, SRP045409 and SRP062745

667 (https://www.ncbi.nlm.nih.gov/).

668 Competing interests

669 The authors declare that they have no competing interests

$670 \quad$ Funding

671 No Funding.

672 Author's contribution 
673 SKU conceived the idea. AS and SKU designed the experiments. AS performed the experiments. 674 AS and HS analyzed the data. AS and HS wrote the manuscript, and AS, HS and SKU finalized 675 the manuscript.

\section{Acknowledgement}

677 Authors are grateful to Panjab University, Chandigarh, India for research facilities, Ensembl 678 Plants, URGI and NCBI for data availability. AS and HS is grateful to CSIR for the senior 679 research fellowship. HS is also thankful to IKGPTU, Jalandhar for Ph.D registration.

680

681 


\section{References}

1. Kombrink E, Somssich IE. Pathogenesis-Related Proteins and Plant Defense. In: Plant Relationships. Berlin, Heidelberg: Springer Berlin Heidelberg; 1997. p. 107-28. doi:10.1007/978-3-662-10370-8_7.

2. Chadha P, Das RH. A pathogenesis related protein, AhPR10 from peanut: an insight of its mode of antifungal activity. Planta. 2006;225:213-22. doi:10.1007/s00425-006-03447.

3. van Loon LC, Rep M, Pieterse CMJ. Significance of Inducible Defense-related Proteins in Infected Plants. Annu Rev Phytopathol. 2006;44:135-62. doi:10.1146/annurev.phyto.44.070505.143425.

4. Christensen AB, Cho BH, Naesby M, Gregersen PL, Brandt J, Madriz-Ordenana K, et al. The molecular characterization of two barley proteins establishes the novel PR-17 family of pathogenesis-related proteins. Mol Plant Pathol. 2002;3:135-44. doi:10.1046/j.13643703.2002.00105.x.

5. Velazhahan R, Datta SK, Muthukrishnan S. The PR-5 family: Thaumatin-like proteins. In: Pathogenesis-Related Proteins in Plants. CRC Press; 1999. p. 107-29. doi:10.1201/9781420049299.

6. van der Wel H, Loeve K. Isolation and characterization of thaumatin I and II, the sweettasting proteins from Thaumatococcus daniellii Benth. Eur J Biochem. 1972; 31:221-5. doi:10.1111/j.1432-1033.1972.tb02522.x.

7. Kitajima S, Sato F. Plant pathogenesis-related proteins: molecular mechanisms of gene expression and protein function. $\mathrm{J}$ Biochem. 1999; 125:1-8. http://www.ncbi.nlm.nih.gov/pubmed/9880788. Accessed 25 Feb 2019.

8. Brandazza A, Angeli S, Tegoni M, Cambillau C, Pelosi P. Plant stress proteins of the thaumatin-like family discovered in animals. FEBS Lett. 2004; 572:3-7. doi:10.1016/j.febslet.2004.07.003.

9. Grenier J, Potvin C, Trudel J, Asselin A. Some thaumatin-like proteins hydrolyse polymeric beta-1,3-glucans. Plant J. 1999;19:473-80. doi:10.1046/j.1365313X.1999.00551.x.

10. Sakamoto Y, Watanabe H, Nagai M, Nakade K, Takahashi M, Sato T. Lentinula edodes tlg1 Encodes a Thaumatin-Like Protein That Is Involved in Lentinan Degradation and 
Fruiting Body Senescence. PLANT Physiol. 2006;141:793-801. doi:10.1104/pp.106.076679.

11. Shatters RG, Boykin LM, Lapointe SL, Hunter WB, Weathersbee AA. Phylogenetic and Structural Relationships of the PR5 Gene Family Reveal an Ancient Multigene Family Conserved in Plants and Select Animal Taxa. J Mol Evol. 2006;63:12-29. doi:10.1007/s00239-005-0053-z.

12. Liu J-J, Sturrock R, Ekramoddoullah AKM. The superfamily of thaumatin-like proteins: its origin, evolution, and expression towards biological function. Plant Cell Rep. 2010a;29:419-36. doi:10.1007/s00299-010-0826-8.

13. Cao J, Lv Y, Hou Z, Li X, Ding L. Expansion and evolution of thaumatin-like protein (TLP) gene family in six plants. Plant Growth Regul. 2016;79:299-307. doi:10.1007/s10725-015-0134-y.

14. Liu J-J, Zamani A, Ekramoddoullah AKM. Expression profiling of a complex thaumatinlike protein family in western white pine. Planta. 2010b;231:637-51. doi:10.1007/s00425-009-1068-2.

15. Petre B, Major I, Rouhier N, Duplessis S. Genome-wide analysis of eukaryote thaumatinlike proteins (TLPs) with an emphasis on poplar. BMC Plant Biol. 2011;11:33. doi:10.1186/1471-2229-11-33.

16. Fierens E, Gebruers K, Voet ARD, De Maeyer M, Courtin CM, Delcour JA. Biochemical and structural characterization of TLXI, the Triticum aestivum L. thaumatin-like xylanase inhibitor. J Enzyme Inhib Med Chem. 2009;24:646-54. doi:10.1080/14756360802321831.

17. Ghosh R, Chakrabarti C. Crystal structure analysis of NP24-I: a thaumatin-like protein. Planta. 2008;228:883-90. doi:10.1007/s00425-008-0790-5.

18. Smole U, Bublin M, Radauer C, Ebner C, Breiteneder H. Mal d 2, the Thaumatin-Like Allergen from Apple, Is Highly Resistant to Gastrointestinal Digestion and Thermal Processing. Int Arch Allergy Immunol. 2008;147:289-98. doi:10.1159/000144036.

19. Zhao JP, Su XH. Patterns of molecular evolution and predicted function in thaumatin-like proteins of Populus trichocarpa. Planta. 2010;232:949-62. doi:10.1007/s00425-0101218-6. 
20. Rajam MV, Chandola N, Saiprasad Goud P, Singh D, Kashyap V, Choudhary ML, et al. Thaumatin gene confers resistance to fungal pathogens as well as tolerance to abiotic stresses in transgenic tobacco plants. Biol Plant. 2007;51:135-41. doi:10.1007/s10535007-0026-8.

21. Subramanyam K, Arun M, Mariashibu TS, Theboral J, Rajesh M, Singh NK, et al. Overexpression of tobacco osmotin (Tbosm) in soybean conferred resistance to salinity stress and fungal infections. Planta. 2012;236:1909-25. doi:10.1007/s00425-012-1733-8.

22. Acharya K, Pal AK, Gulati A, Kumar S, Singh AK, Ahuja PS. Overexpression of Camellia sinensis Thaumatin-Like Protein, CsTLP in Potato Confers Enhanced Resistance to Macrophomina phaseolina and Phytophthora infestans Infection. Mol Biotechnol. 2013;54:609-22.

23. He R, Wu J, Zhang Y, Agüero CB, Li X, Liu S, et al. Overexpression of a thaumatin-like protein gene from Vitis amurensis improves downy mildew resistance in Vitis vinifera grapevine. Protoplasma. 2017;254:1579-89. doi:10.1007/s00709-016-1047-y.

24. Datta K, Velazhahan R, Oliva N, Ona I, Mew T, Khush GS, et al. Over-expression of the cloned rice thaumatin-like protein (PR-5) gene in transgenic rice plants enhances environmental friendly resistance to Rhizoctonia solani causing sheath blight disease. Theor Appl Genet. 1999;98:1138-45. doi:10.1007/s001220051178.

25. Wang X, Tang C, Deng L, Cai G, Liu X, Liu B, et al. Characterization of a pathogenesisrelated thaumatin-like protein gene TaPR5 from wheat induced by stripe rust fungus. Physiol Plant. 2010;139:27-38. doi:10.1111/j.1399-3054.2009.01338.x.

26. Osmond RI, Hrmova M, Fontaine F, Imberty A, Fincher GB. Binding interactions between barley thaumatin-like proteins and (1,3)-beta-D-glucans. Kinetics, specificity, structural analysis and biological implications. Eur J Biochem. 2001;268:4190-9. http://www.ncbi.nlm.nih.gov/pubmed/11488912. Accessed 25 Feb 2019.

27. Abad LR, D’Urzo MP, Liu D, Narasimhan ML, Reuveni M, Zhu JK, et al. Antifungal activity of tobacco osmotin has specificity and involves plasma membrane permeabilization. Plant Sci. 1996;118:11-23.

28. Yu X-M, Griffith M. Antifreeze proteins in winter rye leaves form oligomeric complexes. Plant Physiol. 1999;119:1361-70. http://www.ncbi.nlm.nih.gov/pubmed/10198095. Accessed 25 Feb 2019. 
29. Zhu B, Chen TH, Li PH. Expression of three osmotin-like protein genes in response to osmotic stress and fungal infection in potato. Plant Mol Biol. 1995;28:17-26. http://www.ncbi.nlm.nih.gov/pubmed/7787181. Accessed 25 Feb 2019.

30. Zhang Y, Shih DS. Isolation of an osmotin-like protein gene from strawberry and analysis of the response of this gene to abiotic stresses. J Plant Physiol. 2007;164:68-77. doi:10.1016/j.jplph.2006.02.002.

31. Neale AD, Wahleithner JA, Lund M, Bonnett HT, Kelly A, Meeks-Wagner DR, et al. Chitinase, [beta]-1,3-Glucanase Osmotin, and Extensin Are Expressed in Tobacco Explants during Flower Formation. The Plant Cell. 1990;2:673-84. doi:10.1105/tpc.2.7.673.

32. Salzman RA, Tikhonova I, Bordelon BP, Hasegawa PM, Bressan RA. Coordinate accumulation of antifungal proteins and hexoses constitutes a developmentally controlled defense response during fruit ripening in grape. Plant Physiol. 1998;117:465-72. http://www.ncbi.nlm.nih.gov/pubmed/9625699. Accessed 25 Feb 2019.

33. Seo PJ, Lee A-K, Xiang F, Park C-M. Molecular and Functional Profiling of Arabidopsis Pathogenesis-Related Genes: Insights into Their Roles in Salt Response of Seed Germination. Plant Cell Physiol. 2008;49:334-44. doi:10.1093/pcp/pcn011.

34. Ellegren H. Comparative genomics and the study of evolution by natural selection. Molecular Ecology. 2008;17:4586-96. doi:10.1111/j.1365-294X.2008.03954.x.

35. Huang S, Sirikhachornkit A, Su X, Faris J, Gill B, Haselkorn R, et al. Genes encoding plastid acetyl-CoA carboxylase and 3-phosphoglycerate kinase of the Triticum/Aegilops complex and the evolutionary history of polyploid wheat. Proc Natl Acad Sci U S A. 2002;99:8133-8. doi:10.1073/pnas.072223799.

36. Sharma M, Singh A, Shankar A, Pandey A, Baranwal V, Kapoor S, et al. Comprehensive expression analysis of rice Armadillo gene family during abiotic stress and development. DNA Res. 2014;21:267-83. doi: 10.1093/dnares/dst056.

37. Tajima F. Simple methods for testing the molecular evolutionary clock hypothesis. Genetics. 1993;135.

38. Choulet F, Alberti A, Theil S, Glover NM, Barbe V, Daron J, et al. Structural and Functional Partitioning of Bread Wheat Chromosome 3B. doi:10.1126/science.1249721ï. 
39. Pingault L, Choulet F, Alberti A, Glover N, Wincker P, Feuillet C, et al. Deep transcriptome sequencing provides new insights into the structural and functional organization of the wheat genome. Genome Biol. 2015;16:29. doi:10.1186/s13059-0150601-9.

40. Papatheodorou I, Fonseca NA, Keays M, Tang YA, Barrera E, Bazant W, et al. Expression Atlas: gene and protein expression across multiple studies and organisms. Nucleic Acids Res. 2018;46:D246-D251. doi:10.1093/nar/gkx1158.

41. Zhang H, Yang Y, Wang C, Liu M, Li H, Fu Y, et al. Large-scale transcriptome comparison reveals distinct gene activations in wheat responding to stripe rust and powdery mildew. BMC Genomics. 2014;15:898. doi:10.1186/1471-2164-15-898.

42. Liu Z, Xin M, Qin J, Peng H, Ni Z, Yao Y, et al. Temporal transcriptome profiling reveals expression partitioning of homeologous genes contributing to heat and drought acclimation in wheat (Triticum aestivum L.). BMC Plant Biol. 2015;15:152. doi:10.1186/s12870-015-0511-8.

43. Zhang Y, Liu Z, Khan AA, Lin Q, Han Y, Mu P, et al. Expression partitioning of homeologs and tandem duplications contribute to salt tolerance in wheat (Triticum aestivum L.). Sci Rep. 2016;6:21476. doi:10.1038/srep21476.

44. Wang Q, Li F, Zhang X, Zhang Y, Hou Y, Zhang S, et al. Purification and Characterization of a CkTLP Protein from Cynanchum komarovii Seeds that Confers Antifungal Activity. PLoS One. 2011;6:e16930. doi:10.1371/journal.pone.0016930.

45. Singh NK, Kumar KRR, Kumar D, Shukla P, Kirti PB. Characterization of a Pathogen Induced Thaumatin-Like Protein Gene AdTLP from Arachis diogoi, a Wild Peanut. PLoS One. 2013;8:e83963. doi:10.1371/journal.pone.0083963.

46. Zhang J, Wang F, Liang F, Zhang Y, Ma L, Wang H, et al. Functional analysis of a pathogenesis-related thaumatin-like protein gene TaLr35PR5 from wheat induced by leaf rust fungus. BMC Plant Biol. 2018;18:76. doi:10.1186/s12870-018-1297-2.

47. Faillace GR, Turchetto-Zolet AC, Guzman FL, de Oliveira-Busatto LA, BodaneseZanettini MH. Genome-wide analysis and evolution of plant thaumatin-like proteins: a focus on the origin and diversification of osmotins. Mol Genet Genomics. 2019;294:1137-57. doi:10.1007/s00438-019-01554-y. 
48. Ahmed NU, Park J-I, Jung H-J, Kang K-K, Lim Y-P, Hur Y, et al. Molecular characterization of thaumatin family genes related to stresses in Brassica rapa. Sci Hortic. 2013;152:26-34. doi:10.1016/j.scienta.2013.01.007.

49. Yan X, Qiao H, Zhang X, Guo C, Wang M, Wang Y, et al. Analysis of the grape (Vitis vinifera L.) thaumatin-like protein (TLP) gene family and demonstration that TLP29 contributes to disease resistance. Sci Rep. 2017;7:4269. doi:10.1038/s41598-017-04105W.

50. Marcussen T, Sandve SR, Heier L, Spannagl M, Pfeifer M, Jakobsen KS, et al. Ancient hybridizations among the ancestral genomes of bread wheat. Science. 2014;345:1250092-1250092. doi:10.1126/science.1250092.

51. Kondrashov FA. Gene duplication as a mechanism of genomic adaptation to a changing environment. Proc R Soc B Biol Sci. 2012;279:5048-57. doi:10.1098/rspb.2012.1108.

52. Magadum S, Banerjee U, Murugan P, Gangapur D, Ravikesavan R. Gene duplication as a major force in evolution. J Genet. 2013;92:155-61. http://www.ncbi.nlm.nih.gov/pubmed/23640422. Accessed 28 Jul 2019.

53. Appels R, Eversole K, Stein N, Feuillet C, Keller B, Rogers J, et al. Shifting the limits in wheat research and breeding using a fully annotated reference genome. Science. 2018;361:eaar7191. doi:10.1126/science.aar7191.

54. Gaut BS. Evolutionary dynamics of grass genomes. New Phytologist. 2002;154:15-28. doi:10.1046/j.1469-8137.2002.00352.x.

55. Yang YW, Lai KN, Tai PY, Li WH. Rates of nucleotide substitution in angiosperm mitochondrial DNA sequences and dates of divergence between Brassica and other angiosperm lineages. J Mol Evol. 1999;48:597-604. doi:10.1007/PL00006502.

56. Paterson AH, Bowers JE, Chapman BA. Ancient polyploidization predating divergence of the cereals, and its consequences for comparative genomics. Proc Natl Acad Sci U S A. 2004;101:9903-8.

57. Liu Y, Cui J, Zhou X, Luan Y, Luan F. Genome-wide identification, characterization and expression analysis of the TLP gene family in melon (Cucumis melo L.). Genomics. 2020;112:2499-509. 
58. Parry G, Ward S, Cernac A, Dharmasiri S, Estelle M. The Arabidopsis suppressor of auxin resistance proteins are nucleoporins with an important role in hormone signaling and development. Plant Cell. 2006;18:1590-603. doi:10.1105/tpc.106.041566.

59. Zhang Y, Li X. A putative nucleoporin 96 is required for both basal defense and constitutive resistance responses mediated by suppressor of npr1-1, constitutive 1. Plant Cell. 2005;17:1306-16. doi:10.1105/tpc.104.029926.

60. Koiwa H, Kato H, Nakatsu T, Oda J, Yamada Y, Sato F. Crystal structure of tobacco PR-5d protein at $1.8 \AA$ resolution reveals a conserved acidic cleft structure in antifungal thaumatin-like proteins 1 1Edited by R. Huber. J Mol Biol. 1999;286:1137-45. doi:10.1006/jmbi.1998.2540.

61. Leone P, Menu-Bouaouiche L, Peumans WJ, Payan F, Barre A, Roussel A, et al. Resolution of the structure of the allergenic and antifungal banana fruit thaumatin-like protein at 1.7- . Biochimie. 2006;88:45-52. doi:10.1016/j.biochi.2005.07.001.

62. Marangon M, Van Sluyter SC, Waters EJ, Menz RI. Structure of Haze Forming Proteins in White Wines: Vitis vinifera Thaumatin-Like Proteins. PLoS One. 2014;9:e113757. doi:10.1371/journal.pone.0113757.

63. Ramos M V., de Oliveira RSB, Pereira HM, Moreno FBMB, Lobo MDP, Rebelo LM, et al. Crystal structure of an antifungal osmotin-like protein from Calotropis procera and its effects on Fusarium solani spores, as revealed by atomic force microscopy: Insights into the mechanism of action. Phytochemistry. 2015;119:5-18. doi:10.1016/j.phytochem.2015.09.012.

64. Singh S, Tripathi RK, Lemaux PG, Buchanan BB, Singh J. Redox-dependent interaction between thaumatin-like protein and $\beta$-glucan influences malting quality of barley. Proc Natl Acad Sci U S A. 2017;114:7725-30. doi:10.1073/pnas.1701824114.

65. Durick K, Mendlein J, Xanthopoulos KG. Hunting with traps: Genome-wide strategies for gene discovery and functional analysis. Genome Research. 1999;9:1019-25. doi:10.1101/gr.9.11.1019.

66. Fils-Lycaon BR, Wiersma PA, Eastwell KC, Sautiere P. A cherry protein and its gene, abundantly expressed in ripening fruit, have been identified as thaumatin-like. Plant Physiol. 1996;111:269-73. doi:10.1104/pp.111.1.269. 
67. Hayashi M, Shiro S, Kanamori H, Mori-Hosokawa S, Sasaki-Yamagata H, Sayama T, et al. A Thaumatin-Like Protein, Rj4, Controls Nodule Symbiotic Specificity in Soybean. Plant Cell Physiol. 2014;55:1679-89. doi:10.1093/pcp/pcu099.

68. Munis MFH, Tu L, Deng F, Tan J, Xu L, Xu S, et al. A thaumatin-like protein gene involved in cotton fiber secondary cell wall development enhances resistance against Verticillium dahliae and other stresses in transgenic tobacco. Biochem Biophys Res Commun. 2010;393:38-44. doi:10.1016/j.bbrc.2010.01.069.

69. Misra RC, Sandeep, Kamthan M, Kumar S, Ghosh S. A thaumatin-like protein of Ocimum basilicum confers tolerance to fungal pathogen and abiotic stress in transgenic Arabidopsis. Sci Rep. 2016;6:25340. doi:10.1038/srep25340.

70. Li XY, Gao L, Zhang WH, Liu JK, Zhang YJ, Wang HY, et al. Characteristic expression of wheat PR5 gene in response to infection by the leaf rust pathogen, Puccinia triticina. J Plant Interact. 2015;10:132-41. doi:10.1080/17429145.2015.1036140.

71. Chen WP, Chen PD, Liu DJ, Kynast R, Friebe B, Velazhahan R, et al. Development of wheat scab symptoms is delayed in transgenic wheat plants that constitutively express a rice thaumatin-like protein gene. Theor Appl Genet. 1999;99:755-60. doi:10.1007/s001220051294.

72. Anand A, Zhou T, Trick HN, Gill BS, Bockus WW, Muthukrishnan S. Greenhouse and field testing of transgenic wheat plants stably expressing genes for thaumatin-like protein, chitinase and glucanase against Fusarium graminearum. J Exp Bot. 2003;54:1101-11. http://www.ncbi.nlm.nih.gov/pubmed/12598580. Accessed 26 Feb 2019.

73. Mackintosh CA, Lewis J, Radmer LE, Shin S, Heinen SJ, Smith LA, et al. Overexpression of defense response genes in transgenic wheat enhances resistance to Fusarium head blight. Plant Cell Rep. 2007;26:479-88. doi:10.1007/s00299-006-0265-8.

74. Kuwabara C, Takezawa D, Shimada T, Hamada T, Fujikawa S, Arakawa K. Abscisic acid- and cold-induced thaumatin-like protein in winter wheat has an antifungal activity against snow mould, Microdochium nivale. Physiol Plant. 2002;115:101-10. doi:10.1034/j.1399-3054.2002.1150112.x.

75. Jayaraj J, Muthukrishnan S, Liang GH, Velazhahan R. Jasmonic acid and salicylic acid induce accumulation of $\beta$-1,3-glucanase and thaumatin-like proteins in wheat and 
enhance resistance against Stagonospora nodorum. Biol Plant. 2004;48:425-30. doi:10.1023/B:BIOP.0000041097.03177.2d.

76. Velazhahan R, Muthukrishnan S. Transgenic Tobacco Plants Constitutively Overexpressing a Rice Thaumatin-like Protein (PR-5) Show Enhanced Resistance to Alternaria Blternata. Biol 2004;47:347-54. doi:10.1023/B:BIOP.0000023876.55053.5e.

77. Safavi K, Zareie R, Tabatabaei BES. Constitutive expression of thaumatin-like protein (TLP-3) in transgenic tobacco plants leads to enhance resistance to Alternaria alternata. Arch Phytopathol Plant Prot. 2012;45:161-9. doi:10.1080/03235408.2010.507947.

78. Odeny Ojola P, Nyaboga EN, Njiru PN, Orinda G. Overexpression of rice thaumatin-like protein (Ostlp) gene in transgenic cassava results in enhanced tolerance to Colletotrichum gloeosporioides f. sp. manihotis. J Genet Eng Biotechnol. 2018;16:125-31. doi:10.1016/J.JGEB.2017.12.002.

79. Mahdavi F, Sariah M, Maziah M. Expression of Rice Thaumatin-Like Protein Gene in Transgenic Banana Plants Enhances Resistance to Fusarium Wilt. Appl Biochem Biotechnol. 2012;166:1008-19. doi:10.1007/s12010-011-9489-3.

80. Naseri G, Sohani MM, Pourmassalehgou A, Allahi S. In planta transformation of rice (Oryza sativa) using thaumatin-like protein gene for enhancing resistance to sheath blight. African J Biotechnol. 2012;11:7885-93. doi:10.5897/AJB11.3331.

81. Liu D, He X, Li W, Chen C, Ge F. Molecular cloning of a thaumatin-like protein gene from Pyrus pyrifolia and overexpression of this gene in tobacco increased resistance to pathogenic fungi. Plant Cell, Tissue Organ Cult. 2012;111:29-39. doi:10.1007/s11240012-0167-0.

82. Hiroyuki K, Terauchi R. Regulation of expression of rice thaumatin-like protein: Inducibility by elicitor requires promoter W-box elements. Plant Cell Rep. 2008;27:1521-8. doi:10.1007/s00299-008-0536-7.

83. Woloshuk CP, Meulenhoff JS, Sela-Buurlage M, van den Elzen PJ, Cornelissen BJ. Pathogen-induced proteins with inhibitory activity toward Phytophthora infestans. Plant Cell. 1991;3:619-28. doi:10.1105/tpc.3.6.619. 
84. Chen K, Fan B, Du L, Chen Z. Activation of hypersensitive cell death by pathogeninduced receptor-like protein kinases from Arabidopsis. Plant Mol Biol. 2004;56:271-83. doi:10.1007/s11103-004-3381-2.

85. Takenaka Y, Nakano S, Tamoi M, Sakuda S, Fukamizo T. Chitinase gene expression in response to environmental stresses in Arabidopsis thaliana: Chitinase inhibitor allosamidin enhances stress tolerance. Biosci Biotechnol Biochem. 2009;73:1066-71. doi:10.1271/bbb.80837.

86. Ng G, Seabolt S, Zhang C, Salimian S, Watkins TA, Lu H. Genetic dissection of salicylic acid-mediated defense signaling networks in Arabidopsis. Genetics. 2011;189:851-9. doi:10.1534/genetics.111.132332.

87. Sharma A, Shumayla, Tyagi S, Alok A, Singh K, Upadhyay SK. Thaumatin-like protein kinases: Molecular characterization and transcriptional profiling in five cereal crops. Plant Sci. 2020;290:110317.

88. Shumayla, Tyagi S, Sharma A, Singh K, Upadhyay SK. Genomic dissection and transcriptional profiling of Cysteine-rich receptor-like kinases in five cereals and functional characterization of TaCRK68-A. Int J Biol Macromol. 2019;134:316-29. doi:10.1016/j.ijbiomac.2019.05.016.

89. Edgar RC. MUSCLE: multiple sequence alignment with high accuracy and high throughput. Nucleic Acids Res. 2004;32:1792-97. doi:10.1093/nar/gkh340.

90. Corpet F. Multiple sequence alignment with hierarchical clustering. Nucleic Acids Res. 1988;16:10881-90. http://www.ncbi.nlm.nih.gov/pubmed/2849754. Accessed 31 Aug 2017.

91. Kumar S, Stecher G, Li M, Knyaz C, Tamura K. MEGA X: Molecular Evolutionary Genetics Analysis across Computing Platforms. Mol Biol Evol. 2018;35:1547-1549. doi: 10.1093/molbev/msy096.

92. Yang J, Zhang Y. I-TASSER server: new development for protein structure and function predictions. $\quad$ Nucleic $\quad$ Acids $\quad$ Res. 2015;43:W174-181. https://academic.oup.com/nar/article/43/W1/W174/2467872. Accessed 17 Jul 2020.

93. Suyama M, Torrents D, Bork P. PAL2NAL: robust conversion of protein sequence alignments into the corresponding codon alignments. Nucleic Acids Res. 2006;34:W609- 

2020.

985

986

987

988

989

990

991

992

993

994

995

996

997

998

999

1000

1001

1002

1003

1004

1005

1006

1007

1008

1009

1010

1011

94. Gaut BS, Morton BR, McCaig BC, Clegg MT. Substitution rate comparisons between grasses and palms: synonymous rate differences at the nuclear gene Adh parallel rate differences at the plastid gene rbcL. Proc Natl Acad Sci USA. 1996;93:10274. doi:10.1073/PNAS.93.19.10274.

95. Hu B, Jin J, Guo A-Y, Zhang H, Luo J, Gao G. GSDS 2.0: an upgraded gene feature visualization $\quad$ server. $\quad$ Bioinformatics. 2015;31:1296-7. doi:10.1093/bioinformatics/btu817.

96. Gasteiger E, Hoogland C, Gattiker A, Duvaud S, Wilkins MR, Appel RD, et al. Protein Identification and Analysis Tools on the ExPASy Server. In: The proteomics protocols handbook. Totawa: Humana Press; 2005. p. 571-607. doi:10.1385/1-59259-890-0:571.

97. Stothard P. The sequence manipulation suite: JavaScript programs for analyzing and formatting protein and DNA sequences. Biotechniques. 2000;28:1102, 1104. doi:10.2144/00286ir01.

98. Nussbaumer T, Martis MM, Roessner SK, Pfeifer M, Bader KC, Sharma S, et al. MIPS PlantsDB: a database framework for comparative plant genome research. Nucleic Acids Res. 2013;41:D1144-51. doi:10.1093/nar/gks1153.

99. Yu CS, Chen YC, Lu CH, Hwang J-K. Prediction of protein subcellular localization. Proteins Struct Funct Bioinforma. 2006;64:643-51. doi:10.1002/prot.21018.

100. King BR, Guda C. ngLOC: an n-gram-based Bayesian method for estimating the subcellular proteomes of eukaryotes. Genome Biol. 2007;8:R68. doi:10.1186/gb-2007-85-r68.

101. Emanuelsson O, Nielsen H, Brunak S, Von Heijne G. Predicting subcellular localization of proteins based on their N-terminal amino acid sequence. J Mol Biol. 2000;300:100516. doi:10.1006/jmbi.2000.3903.

102. Horton P, Park K-J, Obayashi T, Fujita N, Harada H, Adams-Collier CJ, et al. WoLF PSORT: protein localization predictor. Nucleic Acids Res. 2007;35:W585-7. doi:10.1093/nar/gkm259. 
103. Käll L, Krogh A, Sonnhammer EL. A Combined Transmembrane Topology and Signal Peptide Prediction Method. J Mol Biol. 2004;338:1027-36. doi:10.1016/j.jmb.2004.03.016.

104. Cserzo M, Eisenhaber F, Eisenhaber B, Simon I. TM or not TM: transmembrane protein prediction with low false positive rate using DAS-TMfilter. Bioinformatics. 2004;20:1367. doi:10.1093/bioinformatics/btg394.

105. Petersen TN, Brunak S, von Heijne G, Nielsen H. SignalP 4.0: discriminating signal peptides from transmembrane regions. Nat Methods. 2011;8:785-6. doi:10.1038/nmeth.1701.

106. Letunic I, Doerks T, Bork P. SMART: recent updates, new developments and status in 2015. Nucleic Acids Res. 2015;43:D257-60. doi:10.1093/nar/gku949.

107. Bailey TL, Boden M, Buske FA, Frith M, Grant CE, Clementi L, et al. MEME SUITE: tools for motif discovery and searching. Nucleic Acids Res. 2009;37:W202-8. doi:10.1093/nar/gkp335.

108. Higo K, Ugawa Y, Iwamoto M, Higo H. PLACE: a database of plant cis -acting regulatory DNA elements. Nucleic Acids Res. 1998;26(1):358-9.

109. Haas BJ, Papanicolaou A, Yassour M, Grabherr M, Blood PD, Bowden J, et al. De novo transcript sequence reconstruction from RNA-seq using the Trinity platform for reference generation and analysis. Nat Protoc. 2013;8:1494-512. doi:10.1038/nprot.2013.084.

110. Seo J, Gordish-Dressman H, Hoffman EP. An interactive power analysis tool for microarray hypothesis testing and generation. Bioinformatics. 2006;22:808-14. doi:10.1093/bioinformatics/btk052.

111. Nazarov PV, Muller A, Khutko V. Co-expression analysis of large microarray data sets using CoExpress software tool. Conference: WCSB 2010.

112. Bastian M, Heymann S, Jacomy M. Gephi $\square$ : An Open Source Software for Exploring and Manipulating Networks Visualization and Exploration of Large Graphs. Proc. Third Int. SM Conf. 2009. www.aaai.org. Accessed 28 Jul 2019. 


\section{Figure legends}

1041

1042

1043

1044

1045

1046

1047

1048

1049

1050

1051

1052

1053

1054

1055

1056

1057

1058

1059

1060

1061

1062

1063

1064

1065

1066

1067

1068

1069

Fig. 1 Chromosomal distribution and paralogous gene analysis of TLPS in five cereal crops. Image depicts the scattered localization of TLP genes of (a) B. distachyon, (b) O. sativa, (c) $S$. bicolor, (d) T. aestivum and (e) Z. mays on their respective chromosomes. Red lines and blue lines denote the tandem and segmental duplication events, respectively.

Fig. 2 Multiple sequence alignment of few randomly selected long and small TLPs of $B$. distachyon, O. sativa, S. bicolor, T. aestivum and Z. mays with thaumatin protein sequence. Figure shows the alignment of long (OsTLP5, SbTLP2, BdTLP13, ZmTLP13 and TaTLP1-A) and small (BdTLP10, OsTLP25, ZmTLP6, SbTLP29 and TaTLP6-B) TLPs with a thaumatin (P02883.2|THM1_THADA) protein sequence. The characteristic thaumatin signature motif is shown in sky blue box. All the conserved cysteine residues were marked with asterisk. The REDDD motif was marked with red circle. The FF hydrophobic motif and bottom of acidic cleft forming regions are marked with green triangle and brown box, respectively. The conserved regions of thaumatin domain are marked with black line.

Fig. 3 The comparative tertiary configuration analysis of a small and a long TLP of T. aestivum. The image shows the tertiary structure of a small (TaTLP2-A) and a long (TaTLP6-A) TaTLPs (a, b). Figure (a) illustrate the TaTLP2-A and shows the three complete domains, $13 \beta$ strands, four $\alpha$ helix and eight disulphide bonds. Figure (b) is of TaTLP6-A and shows the $11 \beta$ strands, two $\alpha$ helix, five disulphide bond and deletion of domain II. The coils, $\alpha$ helices, $\beta$ strands and disulphide bridges are coloured with green, red, yellow and blue colours, respectively. The ligand binding position are marked with the purple coloured sticks.

Fig. 4 Phylogenetic tree analysis of A. thaliana, B. distachyon, O. sativa. S, bicolor, T. aestivum and Z. mays using full length peptide of TLPs. Figure shows the phylogenetic tree of TLPs, built by maximum likelihood approach with 1000 bootstrap values using MEGAX software. Phylogenetic tree displays the clustering of TLPs of six plant species in I-X different groups, each group is colored differently. The TLPs from each plant are marked with different colour. 
1070

1071

1072

1073

1074

1075

1076

1077

1078

1079

1080

1081

1082

1083

1084

1085

1086

1087

1088

1089

1090

1091

1092

1093

1094

1095

1096

1097

1098

Fig. 5 Expression analysis of TLP genes of B. distachyon (BdTLP), O. sativa (OsTLP). S. bicolor (SbTLP), T. aestivum (TaTLP) and Z. mays (ZmTLP) under various tissue and developmental stages. Heatmaps (a-e) shows the clustering and expression profiling of TLP genes in $B$. distachyon, (b) O. sativa, (c) S. bicolor, (d) T. aestivum and (e) Z. mays. The different clusters were formed on the basis of expression values of TLP genes in respective crop and represents with different colour. The colour bar depict the upregulated and downregulated expression with red and green colours, respectively.

Fig. 6 Expression profiling of TLP genes of $T$. aestivum under biotic and abiotic stress conditions. Heat maps (a-c) shows the clustering and expression profiling of TaTLP genes under (a) Blumeria graminis (Bgt) and Puccinia striiformis (Pst), (b) HS, DS and HD and (c) salt stress conditions. The clustering of TaTLP genes in each heat map is based on their expression pattern in respective stress condition. The colour bar shows the high and low expression with red and green colours, respectively.

Fig. 7 Co-expression network assembly of TLP genes under various tissue and their development stages. Figure (a-e) shows the co-expression web of (a) B. distachyon, (b) O. sativa, (c) $S$. bicolor, (d) T. aestivum and (e) Z. mays TLPS with their interacting partners of respective genome.

Fig. 8 Co-expression analysis of TLP genes of $T$. aestivum under biotic and abiotic stress conditions. Figure (a-c) depict the interaction web of TaTLP genes under (a) biotic (b) HD and (c) salt stress with the other co-expressed transcripts.

Fig. 9 Comparative expression analysis of duplicated gene pairs in T. aestivum. Graphs (a-e) represents the comparative expression pattern of TaTLPs under various tissue and developmental stages. Based on their expression trend, TaTLPS categorized into retention of function (a-c) and pseudo functionalization types $(\mathbf{d}, \mathbf{e})$. 
1099

1100

1101

1102

1103

1104

1105

1106

1107

1108

1109

1110

1111

1112

1113

1114

1115

1116

\section{Additional file 5:}

1118 Table S3. Domain organization of TLP proteins of B. distachyon, O. sativa, S. bicolor, T. aestivum 1119

\section{Additional files}

\section{Additional file 1:}

Table S1. List of identified TLP genes with their proposed nomenclature in $B$. distachyon, $O$. sativa S, bicolor, T. aestivum and Z. mays. The Red colour represents the sTLPS of each crop. (XLSX $16 \mathrm{~kb})$

\section{Additional file 2:}

Figure S1. Multiple sequence alignment of 222 TLPs of B. distachyon, O. sativa, S. bicolor, T. aestivum and Z. mays. Conserved cysteine residues are marked with asterisk. Red dot denotes REDDD motif. The FF hydrophobic motif is highlighted with green triangle. The thaumatin signature motif, conserved domain, amino acids forming the bottom of acidic cleft are marked with sky blue, red and brown lines, respectively. (JPG 15,782 $\mathrm{kb})$

\section{Additional file 3:}

Table S2. List of paralogous TLP genes in B. distachyon, O. sativa, S. bicolor, T. aestivum and Z. mays. (XLXS $12 \mathrm{~kb}$ )

\section{Additional file 4:}

Figure S2. Intron/exon organization and conserved motifs of TLPs of B. distachyon, $O$. sativa, $S$. bicolor, T. aestivum and Z. mays. (JPG $883 \mathrm{~kb}$ ) and Z. mays. (XLXS $22 \mathrm{~kb}$ )

\section{Additional file 6:}

Table S4. The characterization table of B. distachyon, O. sativa, S. bicolor, T. aestivum and $Z$. mays TLPs. (XLXS $33 \mathrm{~kb}$ )

\section{Additional file 7:}

Table S5. List of predicted cis-regulatory elements in the promoter region of TLP genes of $B$. distachyon, O. sativa, S. bicolor, T. aestivum and Z, mays. (DOCX $61 \mathrm{~kb}$ )

\section{Additional file 8:}

Table S6. Annotation and abbreviation of co-expressed genes of B. distachyon, $O$. sativa, $S$. bicolor, T. aestivum and Z. mays under tissue and developmental stages. (XLXS 43 $\mathrm{kb})$ 
bioRxiv preprint doi: https://doi.org/10.1101/2020.09.24.311928; this version posted September 25, 2020. The copyright holder for this preprint (which was not certified by peer review) is the author/funder. All rights reserved. No reuse allowed without permission.

\section{Additional file 9:}

1131 Table S7. Annotation and abbreviation of co-expressed genes of T. aestivum under abiotic and biotic

stress

conditions.

(XLXS

29

$\mathrm{kb})$ 
Table 1 The $\mathrm{Ka} / \mathrm{Ks}$ ratio and divergence time of duplicated TLP gene pairs.

1135

\begin{tabular}{|c|c|c|c|c|c|c|}
\hline Gene A & Gene B & Ka & Ks & $\mathrm{Ka} / \mathrm{Ks}$ & $\begin{array}{l}\text { Selection } \\
\text { pressure }\end{array}$ & $T=K s / 2 r$ \\
\hline$B d T L P K 1$ & $B d T L P K 2$ & 0.1102 & 1.0810 & 0.1020 & Purifying & 83.2 \\
\hline OsTLP5 & OsTLP7 & 0.1014 & 0.6788 & 0.1494 & Purifying & 52.2 \\
\hline OsTLP22 & OsTLP24 & 0.0697 & 0.4134 & 0.3190 & Purifying & 27.7 \\
\hline OsTLP23 & OsTLP25 & 0.1149 & 0.3603 & 0.31646 & Purifying & 29.4 \\
\hline OsTLP26 & OsTLP27 & 0.1569 & 1.3980 & 0.1122 & Purifying & 107.6 \\
\hline SbTLP28 & SbTLP29 & 0.0911 & 0.6808 & 0.1338 & Purifying & 52.4 \\
\hline SbTLP31 & SbTLP34 & 0.1388 & 1.7816 & 0.0779 & Purifying & 137 \\
\hline SbTLP32 & SbTLP33 & 0.0055 & 0.0716 & 0.0771 & Purifying & 5.5 \\
\hline TaTLP1-A & TaTLP24-D & 0.1224 & 0.8739 & 0.1401 & Purifying & 67.2 \\
\hline TaTLP1-B & TaTLP24-B & 0.0937 & 0.8163 & 0.1148 & Purifying & 62.8 \\
\hline TaTLP12-B & TaTLP13-D & 0.1193 & 1.1836 & 0.1008 & Purifying & 91 \\
\hline TaTLP15-A & TaTLP18-B & 0.1368 & 0.9879 & 0.1384 & Purifying & 76 \\
\hline TaTLP15-B2 & TaTLP18-A & 0.1423 & 0.9582 & 0.1486 & Purifying & 73.7 \\
\hline TaTLP16-A & TaTLP17-A & 0.1456 & 1.2825 & 0.1135 & Purifying & 98.7 \\
\hline$Z m T L P 1$ & ZmTLP35 & 0.0955 & 0.3929 & 0.2431 & Purifying & 30.2 \\
\hline ZmTLP2 & ZmTLP34 & 0.1044 & 0.8149 & 0.1281 & Purifying & 62.7 \\
\hline ZmTLP3 & ZmTLP22 & 0.0495 & 0.3036 & 0.1630 & Purifying & 23.4 \\
\hline ZmTLP9 & ZmTLP12 & 0.0767 & 0.3783 & 0.2027 & Purifying & 29.1 \\
\hline ZmTLP13 & ZmTLP37 & 0.0523 & 0.3200 & 0.1634 & Purifying & 24.7 \\
\hline ZmTLP16 & ZmTLP33 & 0.0133 & 0.0141 & 0.9483 & Purifying & 1.1 \\
\hline ZmTLP2O & ZmTLP25 & 0.0797 & 0.0889 & 0.8965 & Purifying & 6.9 \\
\hline
\end{tabular}

1137 Ka- non-synonymous substitutions per non-synonymous site, Ks- synonymous substitutions 1138 per synonymous site, $\mathbf{T}$ - Divergence time 
Table 2 Tajima's relative rate test of paralogous genes.

1143

\begin{tabular}{|c|c|c|c|c|c|c|c|}
\hline Group A & Group B & Out group & $\mathbf{N t}$ & $\mathbf{N a}$ & $\mathrm{Nb}$ & $\chi^{2}$ & $\mathbf{P}$ \\
\hline BdTLP1 & $B d T L P 2$ & BdTLP11 & 403 & 47 & 42 & 0.28 & 0.59611 \\
\hline OsTLP5 & OsTLP7 & OsTLP18 & 401 & 28 & 29 & 0.02 & 0.89463 \\
\hline OsTLP22 & OsTLP24 & OsTLP18 & 333 & 15 & 17 & 0.13 & 0.72367 \\
\hline OsTLP23 & OsTLP25 & OsTLP18 & 313 & 20 & 27 & 1.04 & 0.30723 \\
\hline OsTLP26 & OsTLP27 & OsTLP18 & 411 & 34 & 34 & 0 & 1 \\
\hline$S b T L P 28$ & SbTLP29 & SbTLP5 & 316 & 19 & 30 & 2.47 & 0.11608 \\
\hline SbTLP31 & SbTLP34 & SbTLP5 & 312 & 27 & 32 & 0.42 & 0.51508 \\
\hline SbTLP32 & SbTLP33 & SbTLP5 & 347 & 2 & 2 & 0 & 1 \\
\hline TaTLP1-A & TaTLP24-D & TaTLP4-D & 483 & 37 & 30 & 0.73 & 0.39245 \\
\hline TaTLP1-B & TaTLP24-B & TaTLP4-D & 486 & 36 & 31 & 0.37 & 0.5413 \\
\hline TaTLP12-B & TaTLP13-D & TaTLP4-D & 321 & 24 & 33 & 1.42 & 0.23323 \\
\hline TaTLP15-A & TaTLP18-B & TaTLP4-D & 391 & 36 & 38 & 0.05 & 0.81615 \\
\hline TaTLP15-B2 & TaTLP18-A & TaTLP4-D & 260 & 28 & 27 & 0.02 & 0.89274 \\
\hline TaTLP16-A & TaTLP17-A & TaTLP4-D & 291 & 36 & 31 & 0.37 & 0.5413 \\
\hline ZmTLP1 & ZmTLP35 & ZmTLP28 & 551 & 36 & 33 & 0.13 & 0.71798 \\
\hline$Z m T L P 2$ & ZmTLP34 & ZmTLP28 & 541 & 34 & 25 & 1.37 & 0.24132 \\
\hline ZmTLP3 & ZmTLP22 & ZmTLP28 & 560 & 11 & 14 & 0.36 & 0.54851 \\
\hline ZmTLP9 & ZmTLP12 & ZmTLP28 & 372 & 6 & 12 & 2 & 0.1573 \\
\hline ZmTLP13 & ZmTLP37 & ZmTLP28 & 464 & 19 & 22 & 0.22 & 0.63941 \\
\hline ZmTLP16 & ZmTLP33 & ZmTLP28 & 551 & 5 & 7 & 0.33 & 0.5637 \\
\hline ZmTLP20 & ZmTLP25 & ZmTLP28 & 525 & 17 & 23 & 0.9 & 0.34278 \\
\hline
\end{tabular}

1144

1145 Nt- Identical sites in all three sequences, Na-Unique differences in Sequence A, Nb- Unique 1146 differences in Sequence B 
Table 3 Physicochemical properties of long and small TLP proteins.

1150

\begin{tabular}{ccccccc}
\hline Properties & Type & $\begin{array}{c}\text { Brachypodium } \\
\text { distachyon }\end{array}$ & $\begin{array}{c}\text { Oryza } \\
\text { sativa }\end{array}$ & $\begin{array}{c}\text { Sorghum } \\
\text { bicolor }\end{array}$ & $\begin{array}{c}\text { Triticum } \\
\text { aestivum }\end{array}$ & Zea mays \\
$\begin{array}{c}\text { Average } \\
\text { Protein length }\end{array}$ & Long TLPs & 299 & 289 & 294 & 284 & 334 \\
\hline Average & Long TLPs & 31 & 30 & 30 & 177 & 175 \\
Molecular & Small TLPs & 19.5 & 18.1 & 18.3 & 1822 & 17.7 \\
weight (kDa) & & & & & & 35 \\
\hline Average & Long TLPs & 6.18 & 6.95 & 6.05 & 6.18 & 5.88 \\
pI & Small TLPs & 6.82 & 6.06 & 5.74 & 6.17 & 4.9 \\
\hline
\end{tabular}




$$
\begin{aligned}
& =
\end{aligned}
$$

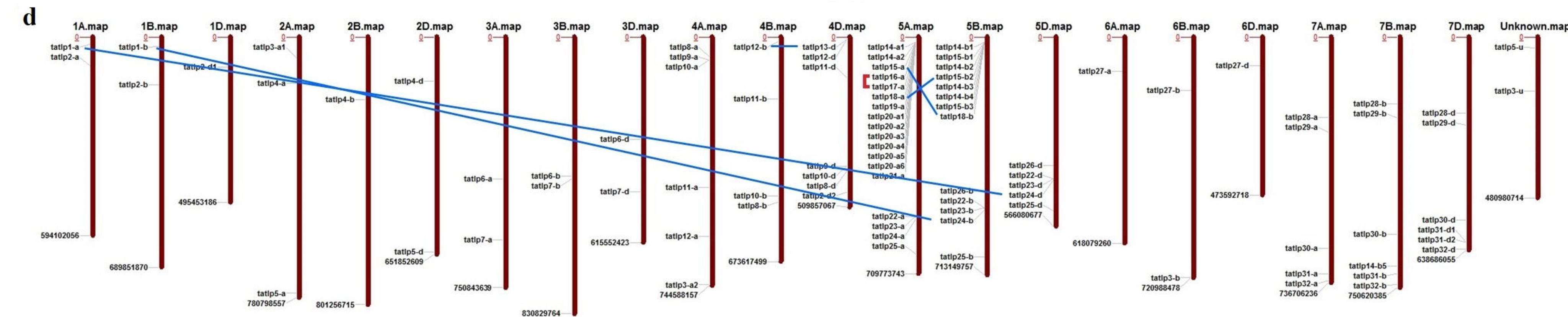

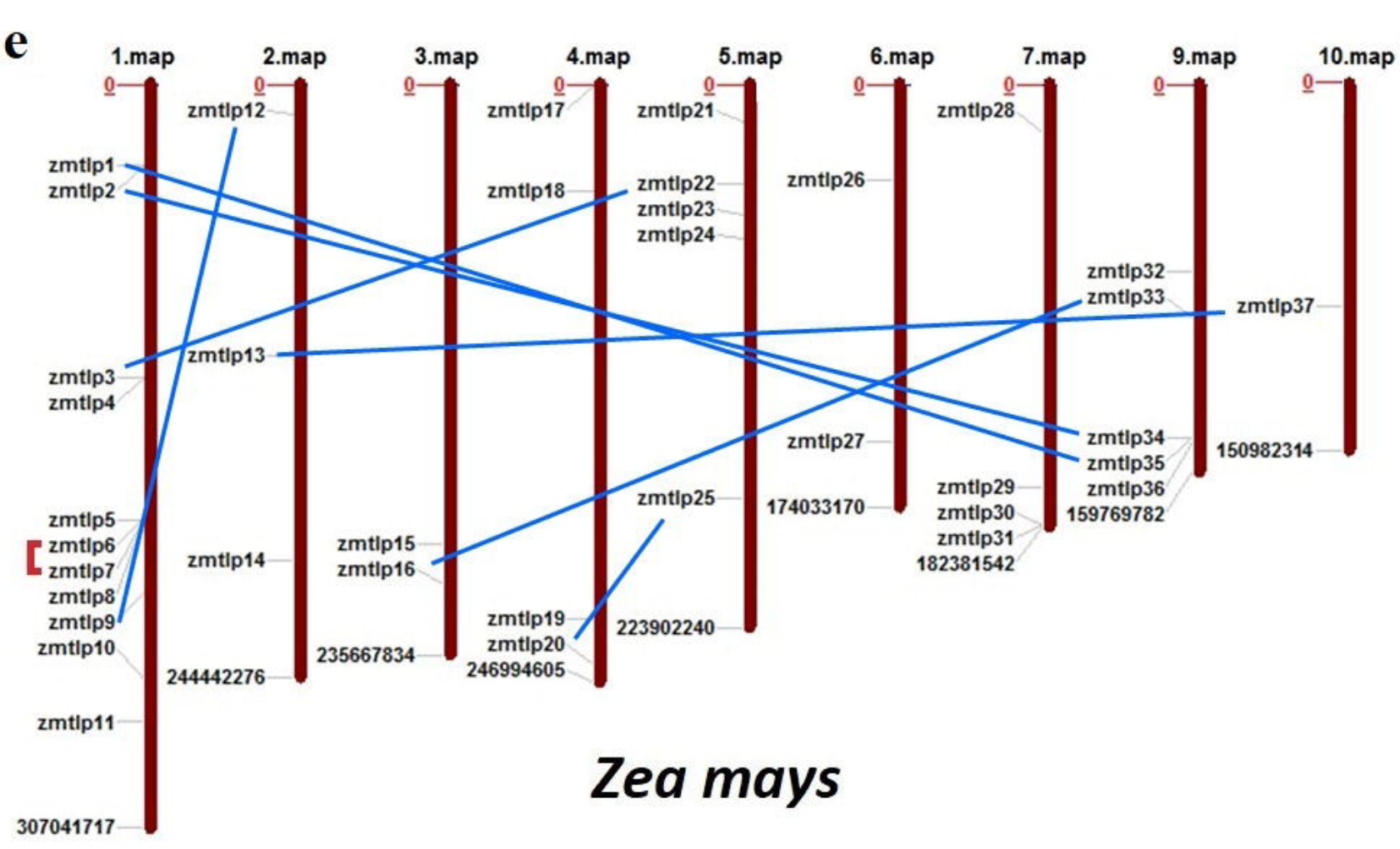


THM1 THAPQ

OSTLP5

RCSYTVHAAASKGDAR--LDAGGROLNSGESH TINYEPGTN-GI KIHARTDCYF-

\section{$\$$}

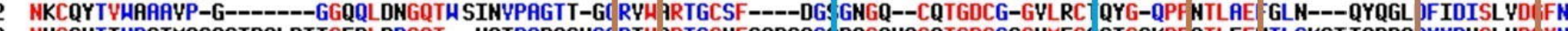
ZnTLP13 NACKHAYHYGALHGASSPPLARSGFYLAPSATS SMDAPSSGTHSI TLH ARTGC-----YADI ATGRFSCATADCGTGDYACI GRGPAPF YSLYE TLA-AP GSGRP JFYDYSLYD IFN TaTLP1-A NECSHPYHYGYLSGATSPQLPRTGFYLAPGGTS SLAAPSSGAHSC NFH ARTGC-----AYDI GTGRLACATADCGSGDYACI GRGPAPF YTLAE TLA-APGSGGL IFYDYSLYDE IFN (1) OsTLP25 NRCSFTYHPAATPY--G-----GGTQLNPGQTH TINYPAGTS-S( RVH BRTGCSF---D-GI GRGR--CATGDCG-GALSCF LSG-QPF LTLAE: TLGTS--GGNR IFYNLSYID YN ZnTLP6 NNCGSTYHPAATPY--G-----GGTQLDPGQTH TYDYPAGTQ-S( RYH IRTGCSF---N-G. GSGS--CQTGDCG-GALSC) LSG-QPF MTLAE: TIG-G--GGSQ JFYDISYID YN NNCSSTYHPAAIPY--G-----GGTQLDPGQTH TYDYPAGT--TC RFH IRTNCSF---Y-G. NRCPFPYCAF -GGAQLAPGETH TLTFARGGT-SI RIH PRHGCAF---HPA GRGG--CQTGDCG-GALRC: LSG

YSG-QPF TTLAE SLGGGSAGGNQ JFYDHSYIE IYN
LSG-KPFATLAE NLAN---GGAP IRYGISYYD(FT

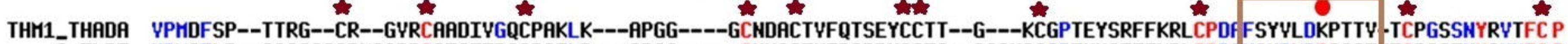
0sTLP5 YPMAFLP--AGSGAGCPKGGPRCATAITPQCPSELR---APGG-----CNNACTYFRQDRYCCTG--SAANSCGPTNYSEFFKRLCPDF YSYPKDDASST 'TCPAGTNYQYYFC P SbTLP2 YPMDFLP--AGDGSGCPKGGPRCDADYTSQCPAALK---ATGG-----CNNPCTYFKTDEYCCTG--SAANTCGPTDYSKFFKGLCPDF YSYPKDDATST 'TCPGGTNYNYYFC P BdTLP13 LPYYAYPRAQQGGGSCN--ATGCAADLNLSCPKELQYEDGIGGSGTYACQSACEAFGKDKYCCSGAYATPTTCSPTAYSSYFKSACPRF YSYAYDDGSSL:TCNA-IDYTIAFC P ZnTLP13 YPYRYAP--SGGGGDCR--PAACAGDYNAYCPGDLRYYASSGG-GYYACKSACIAYGSARYCCTGQYGTPAMCGPTNYSQYFKSACPSF YSYAYDDATST:TCSGPSSYDYTFC

TaTLP1-A LPYSIAP--AHGG--CQ--AAACAGDYNAYCPSDLSYASGSSG-EYYACKSACNAYGSARYCCSGDYGTPAACGPTSYSQYFKAACPAF YSYAYDDASST :TCSAAATYHITFC BdTLP10 YAMDF---_-_-_-_-SCST---G---DALR--

0sTLP25

YAMSF-

ZnTLP6 LAHLF--------------SCST---G---YTLN-

SbTLP29

LPMAF---0---0-----SCST---G---YGLY

LPHDF----------SCSGAGDG---GYIR-

ERS----CPDF YQYPSDDSKLR -SCNGNSNYRYYFC $P$

TaTLP6-B

G-

SPT--_-_--CPAF CLFASDDCRYH -ACSSNSNYOYIFC P

$\star$ Cysteine residue

- REDDD motif

\section{FF hydrophobic motif}

$\square$ Bottom of acidic cleft forming amino acids

\section{Signature motif}

- Thaumatin conserverd domain 


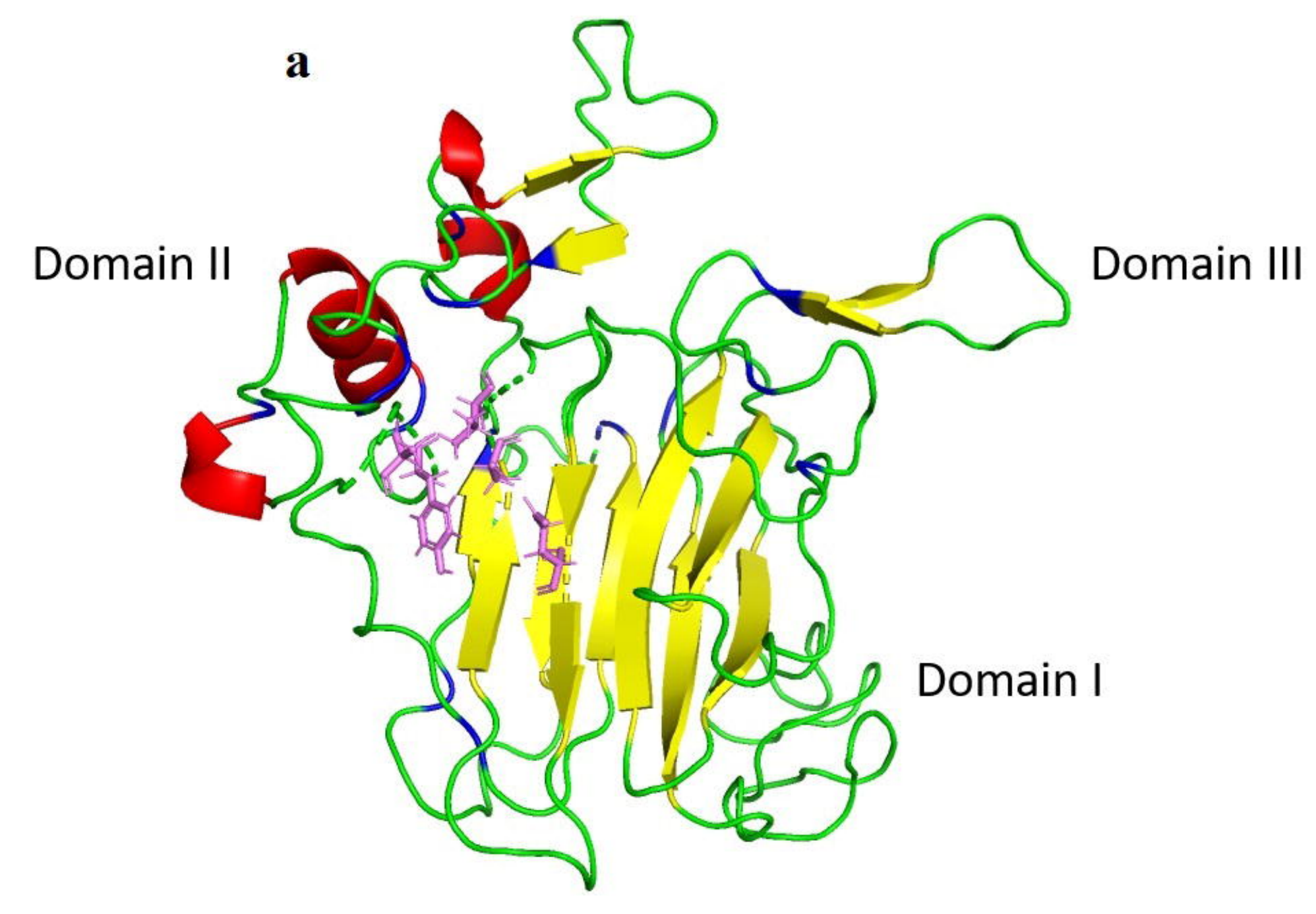

TaTLP2-A

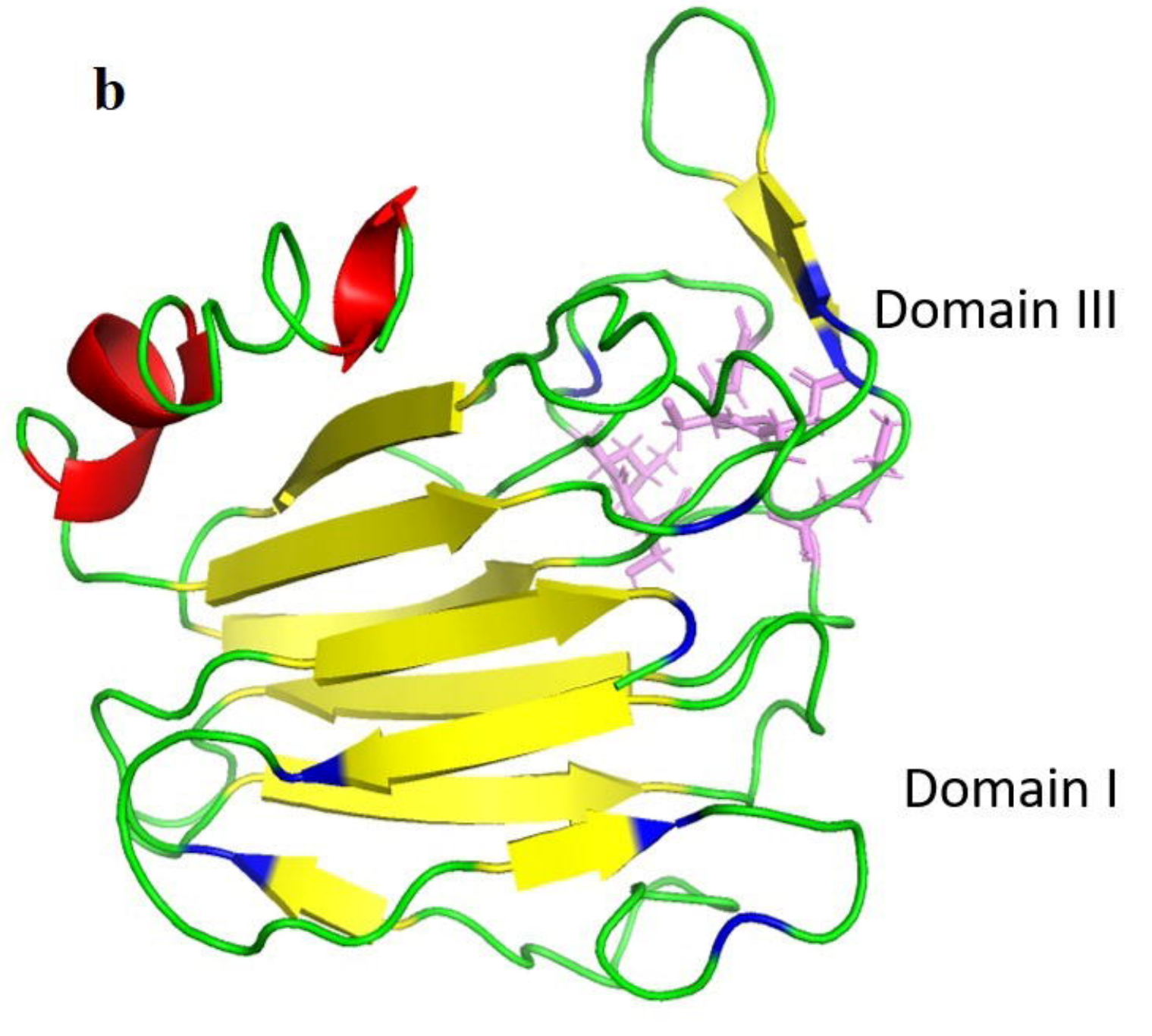

TaTLP6-A 


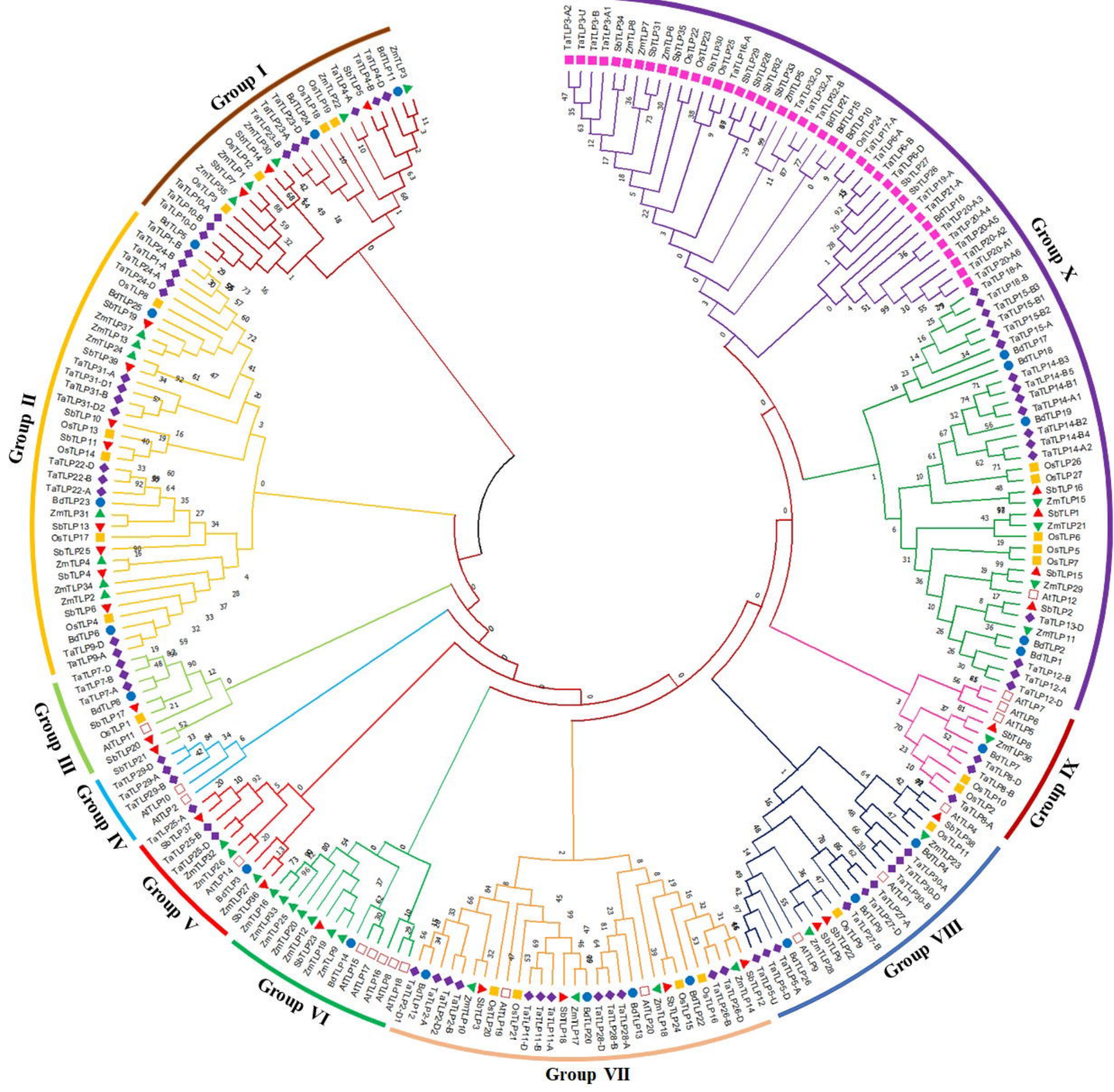




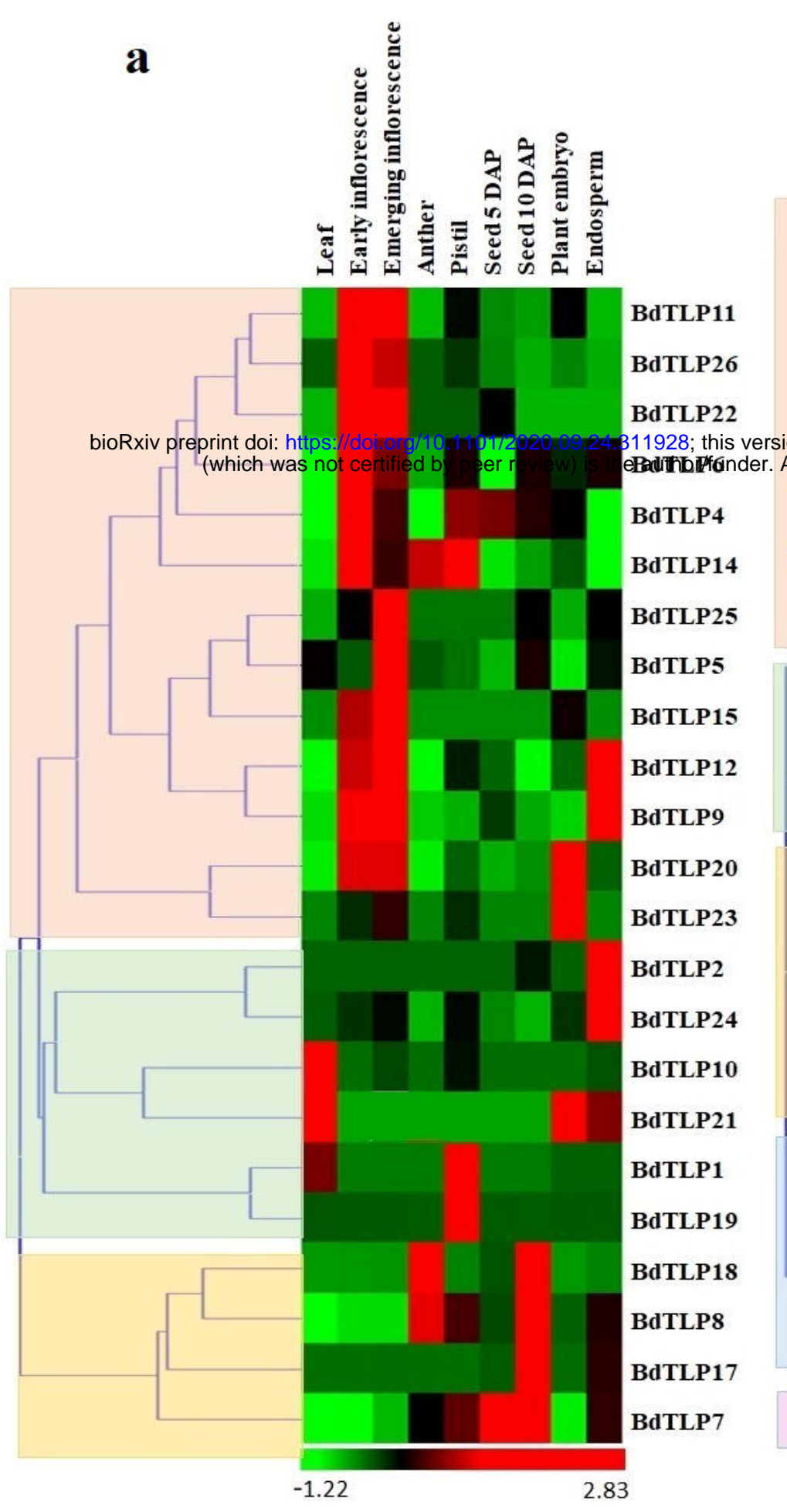

b

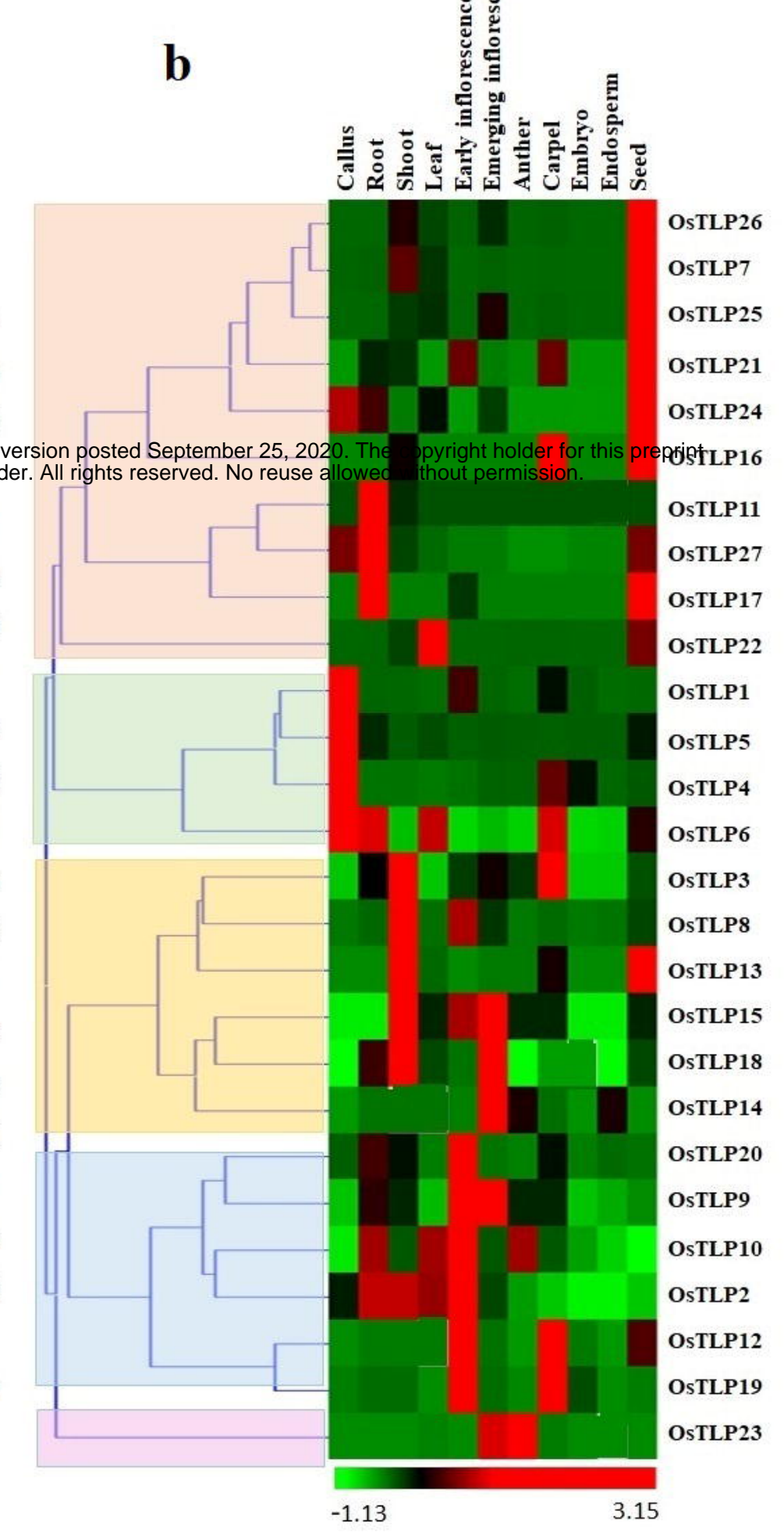

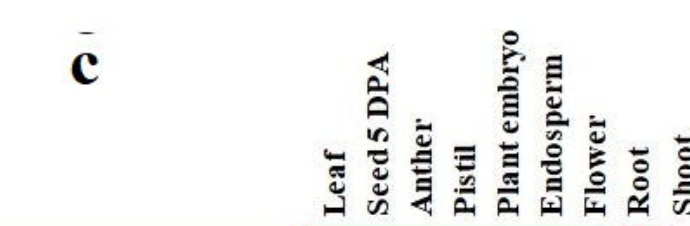

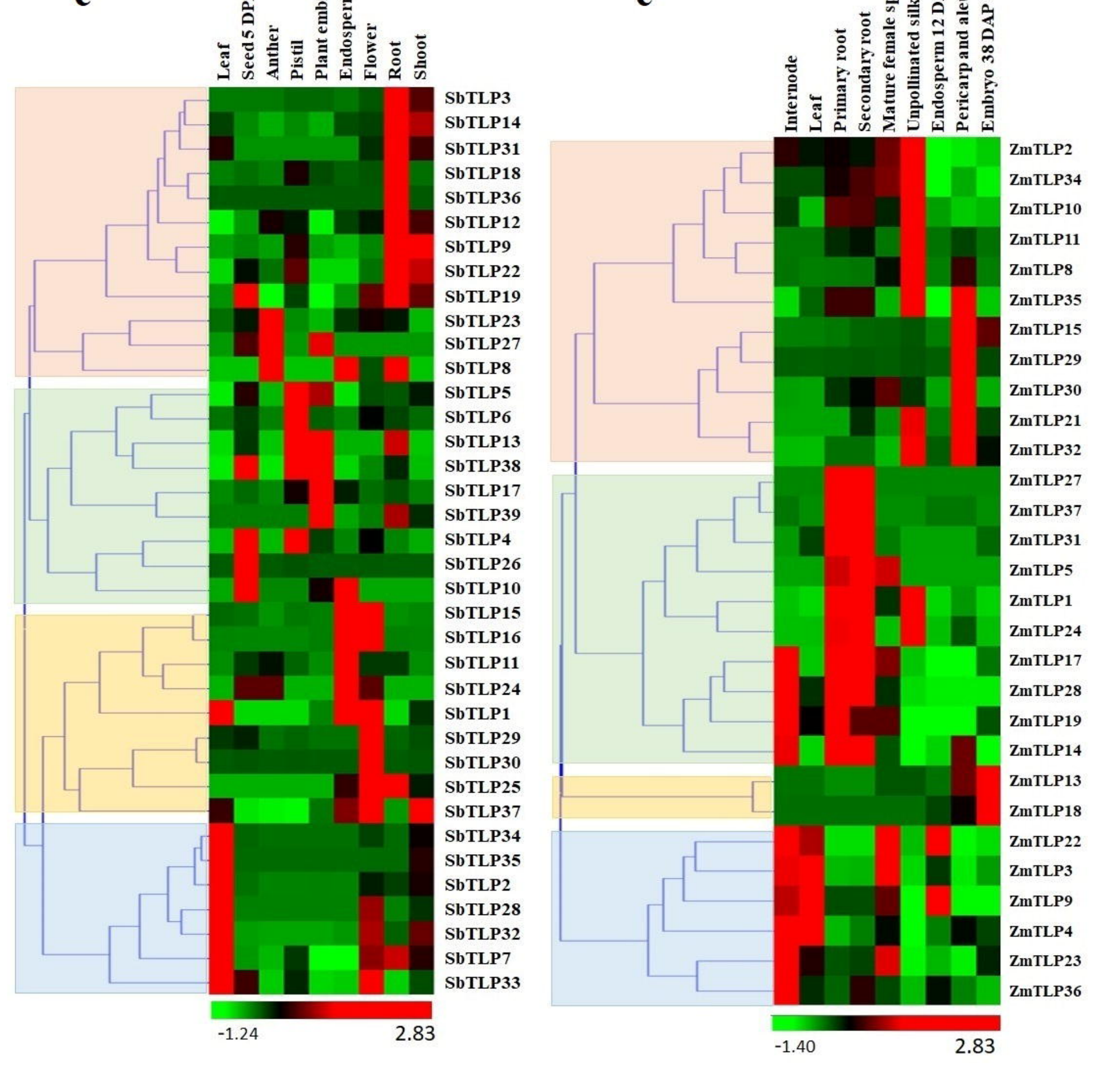

d

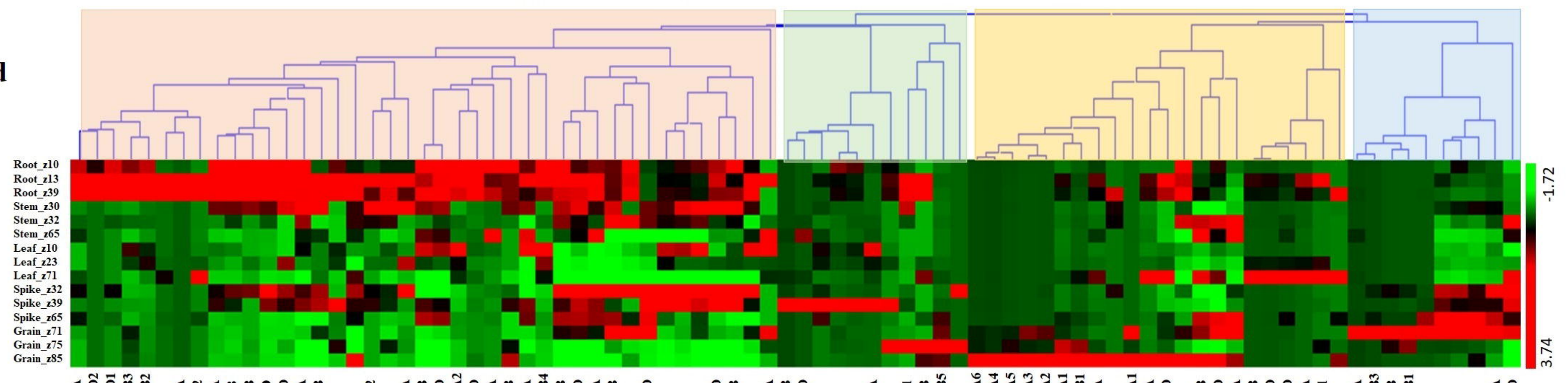

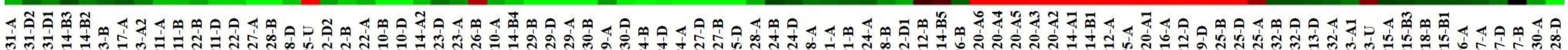

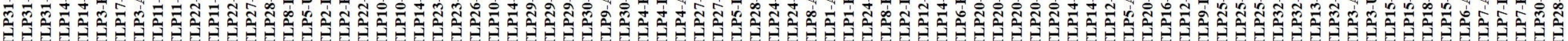

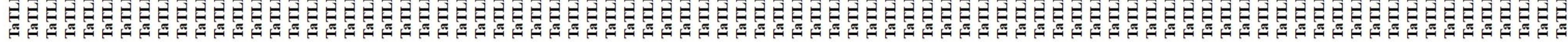


a

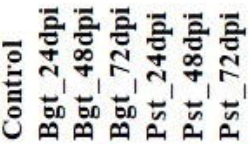

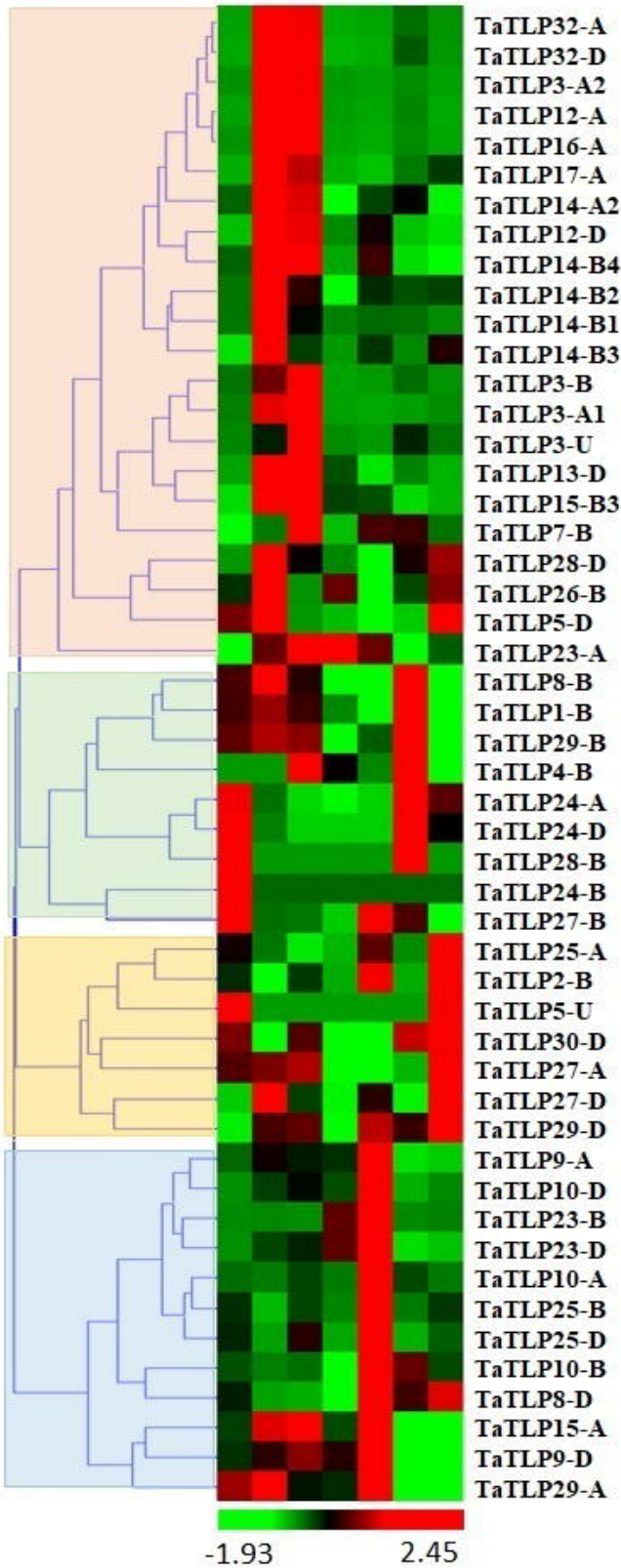

Group 1
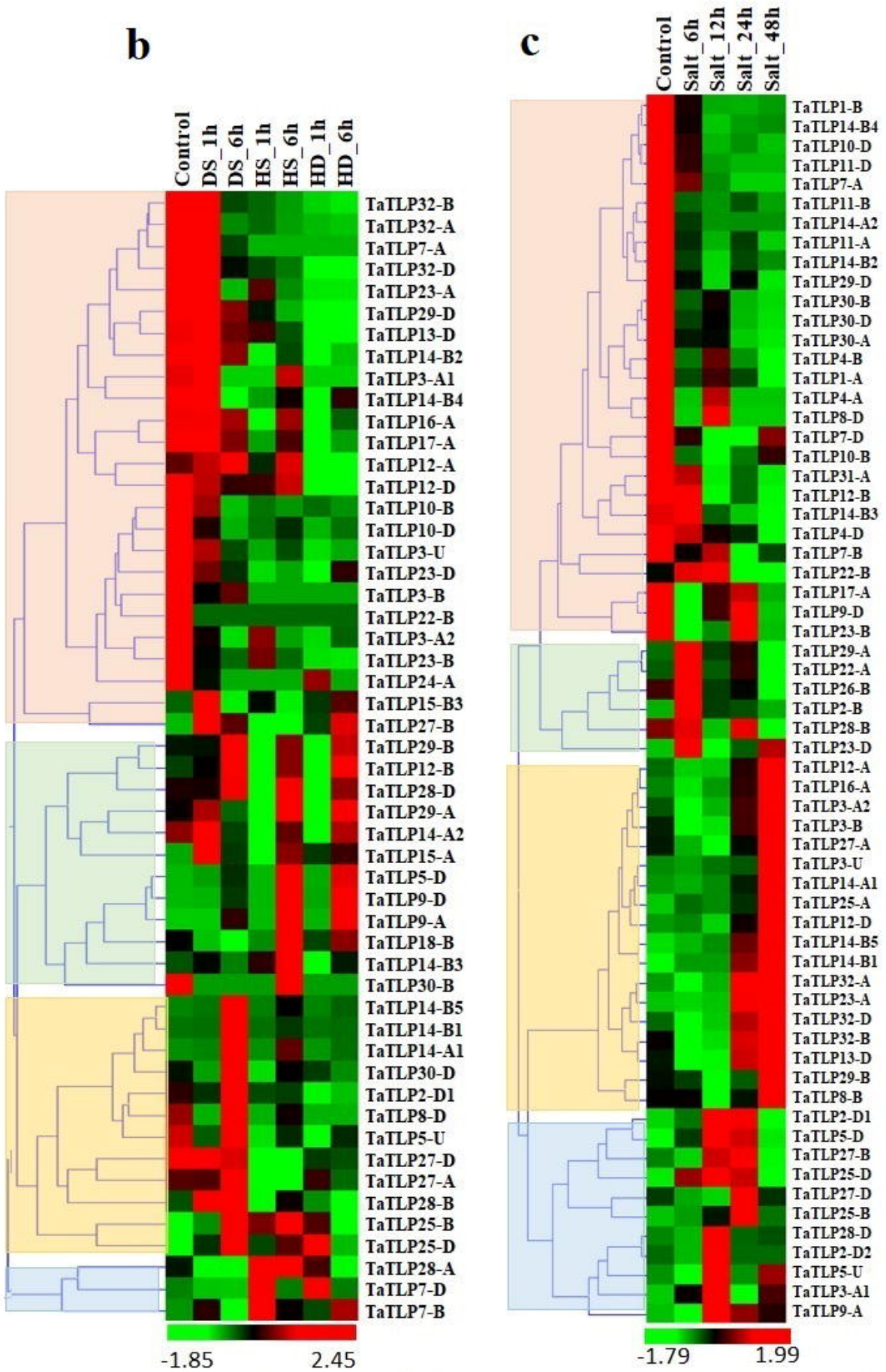

Group 4 


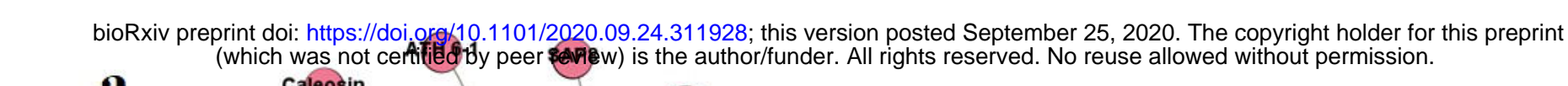

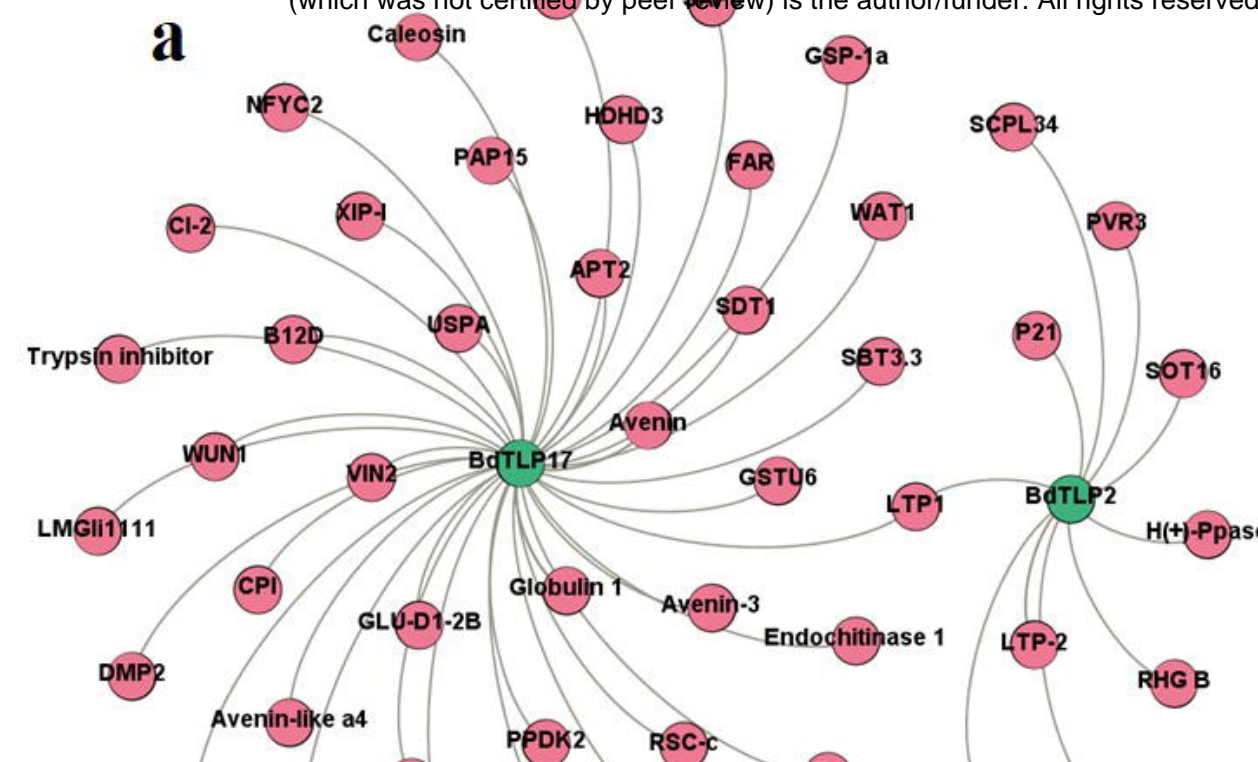

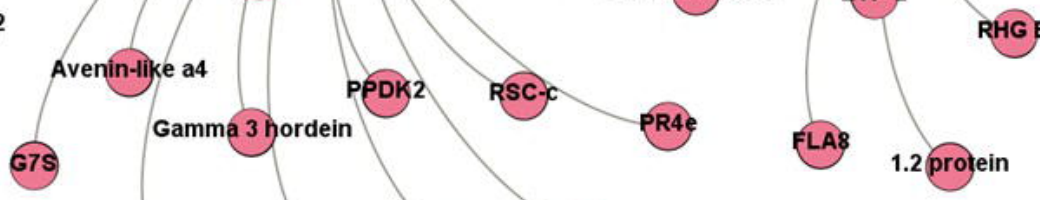
PXe4 Mift Alergen MIP

(PP) BATLP19 BBP3 HSP22.1

\section{d}

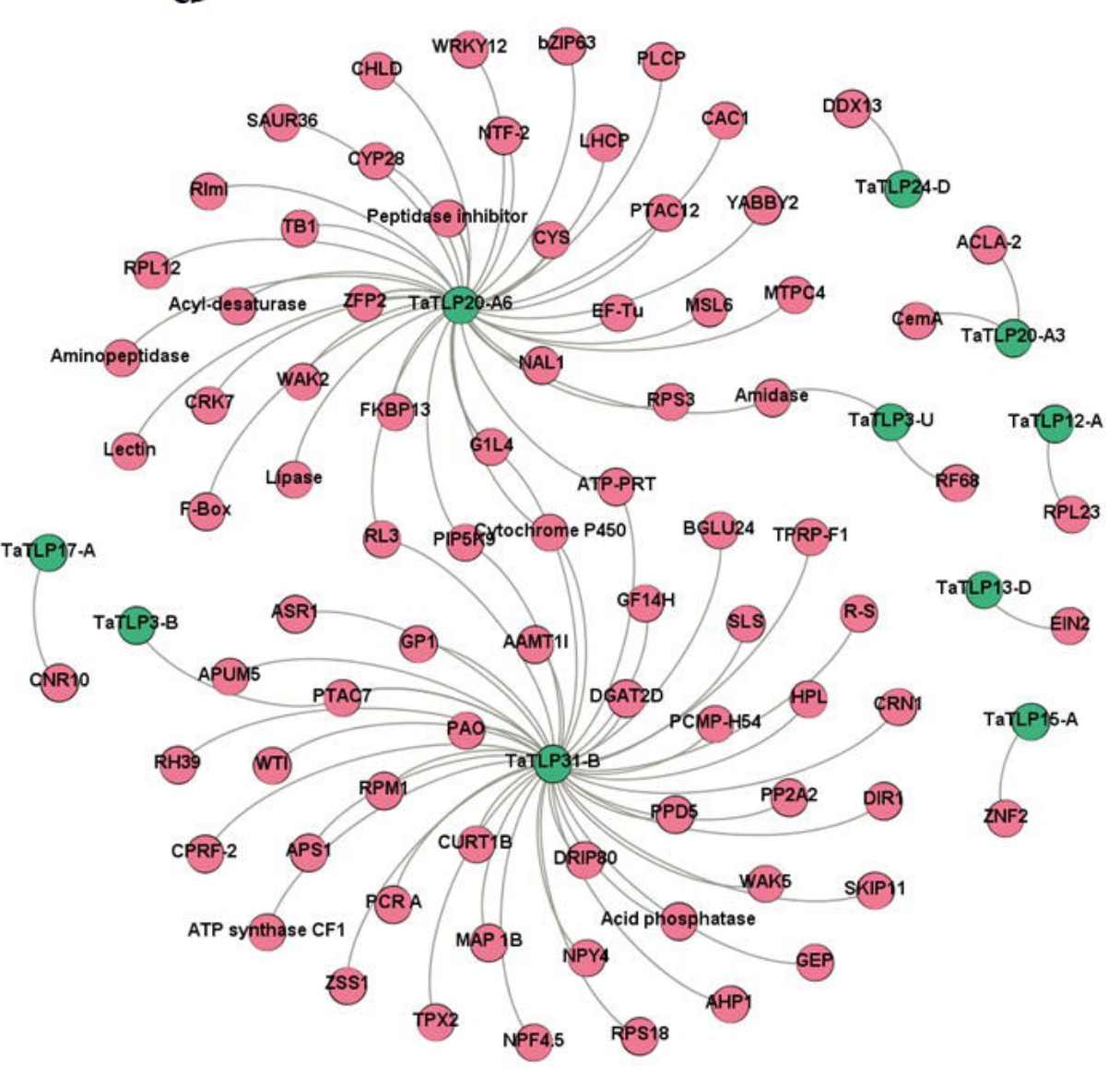

\section{c}

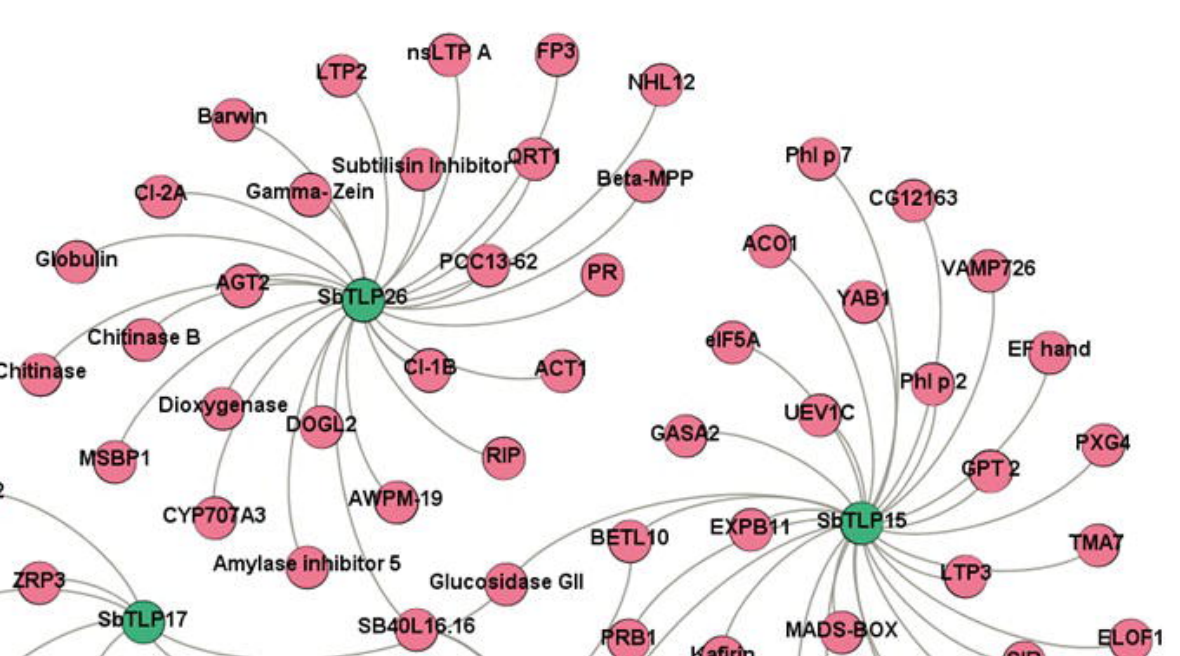

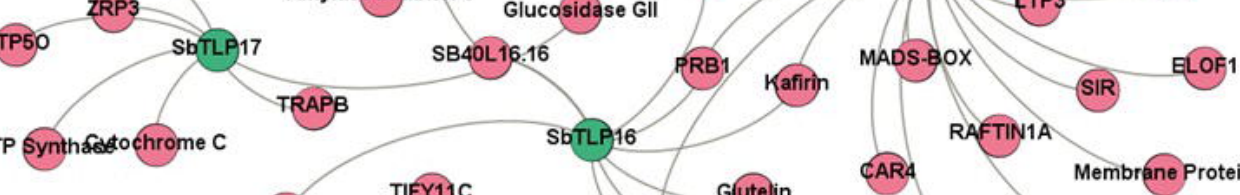

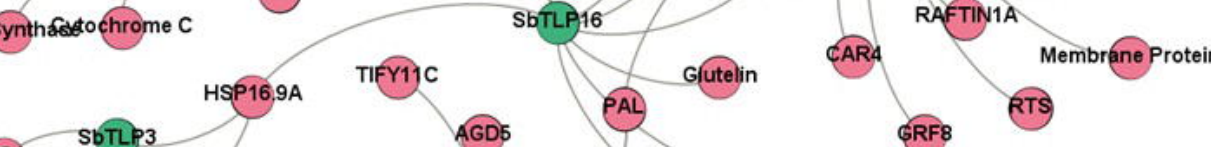

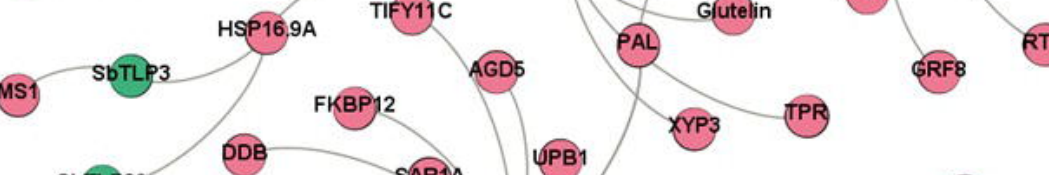

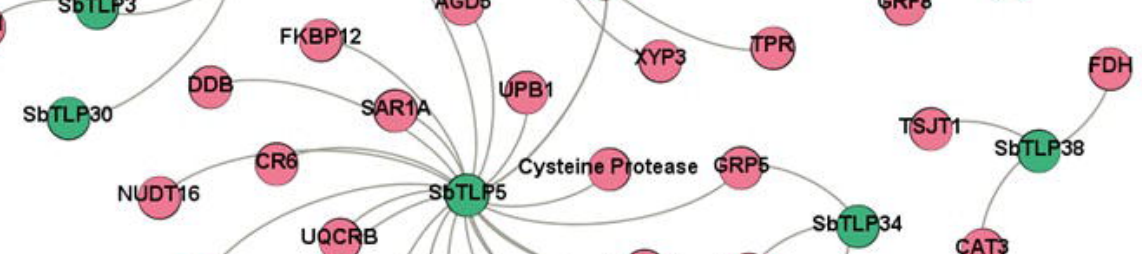

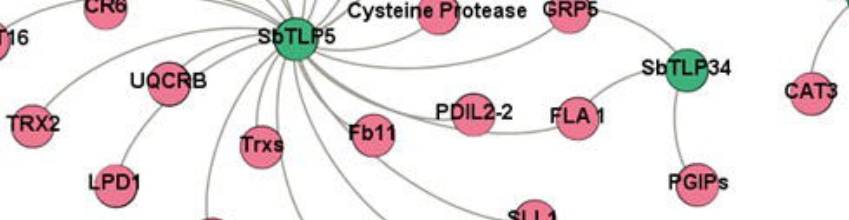

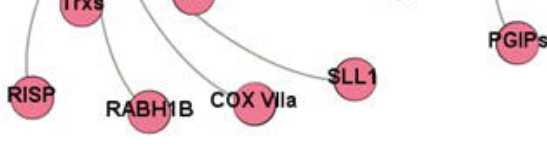

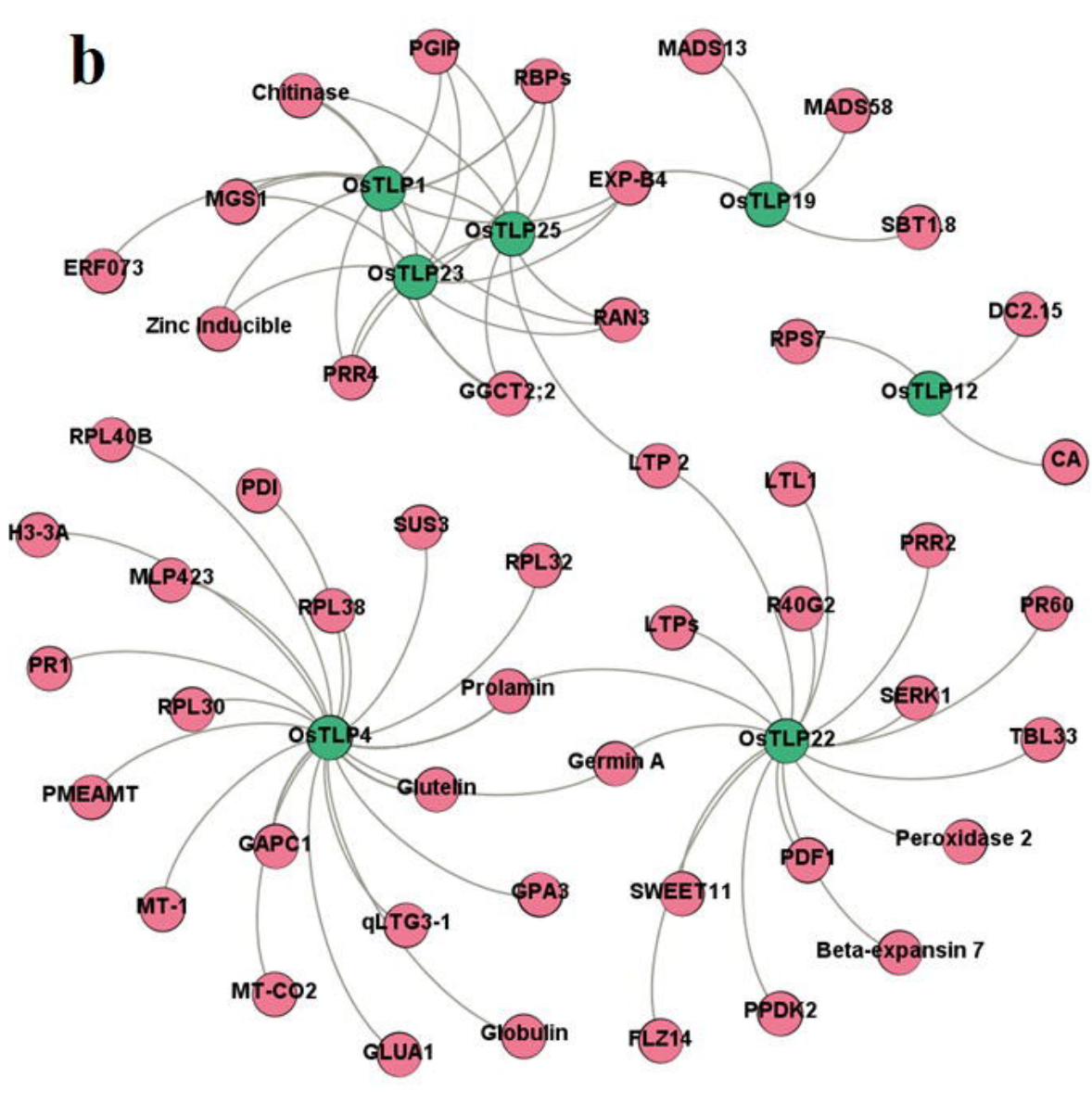

C

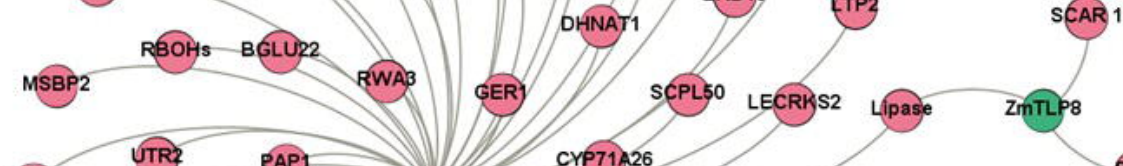

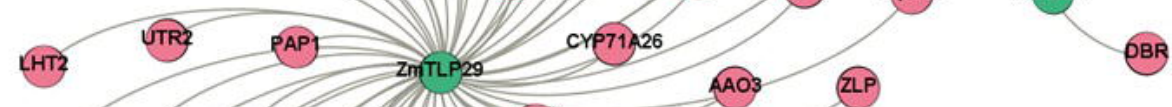

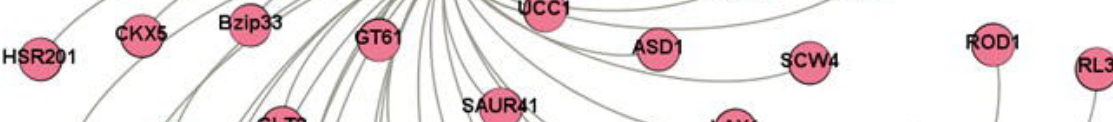

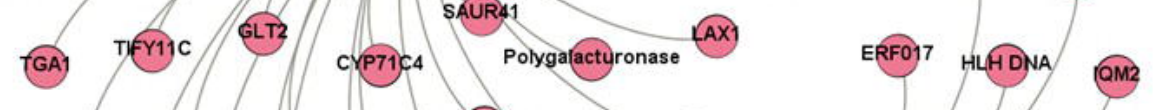

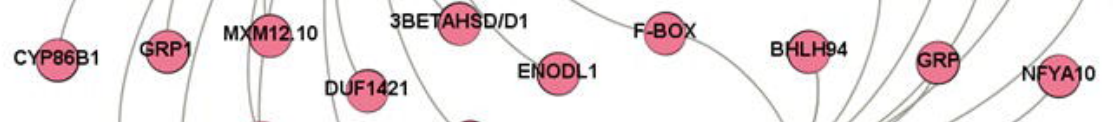
Esterase MIP LKRSDH 


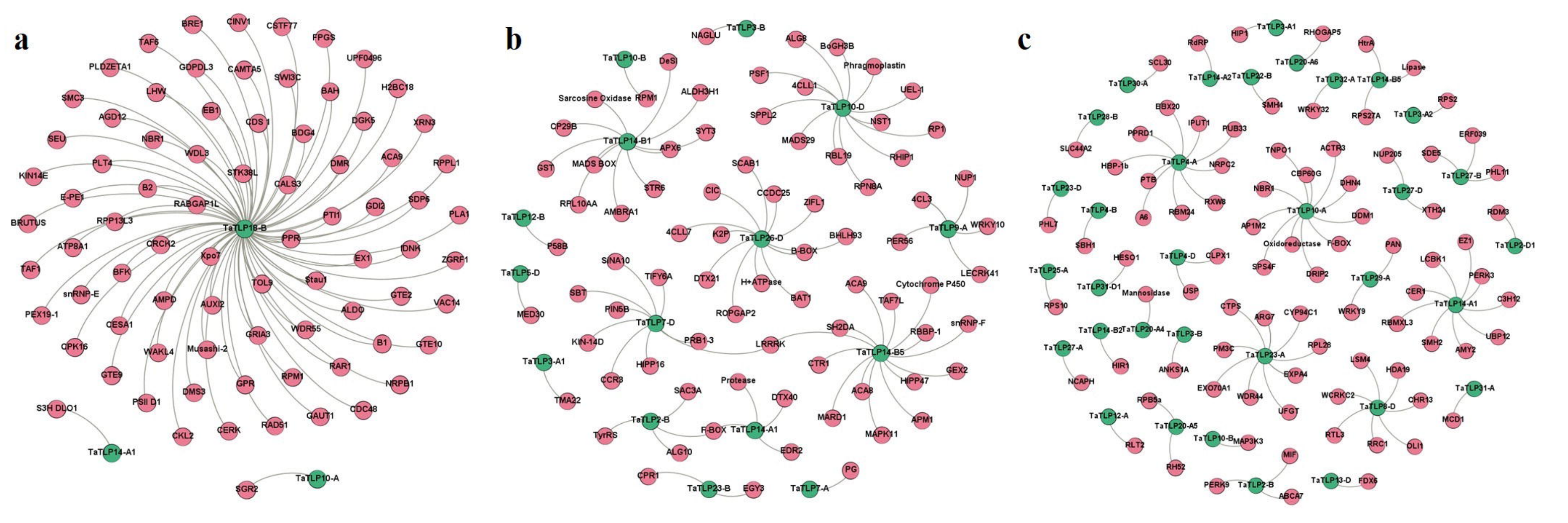


${ }^{12} \mathbf{b}$
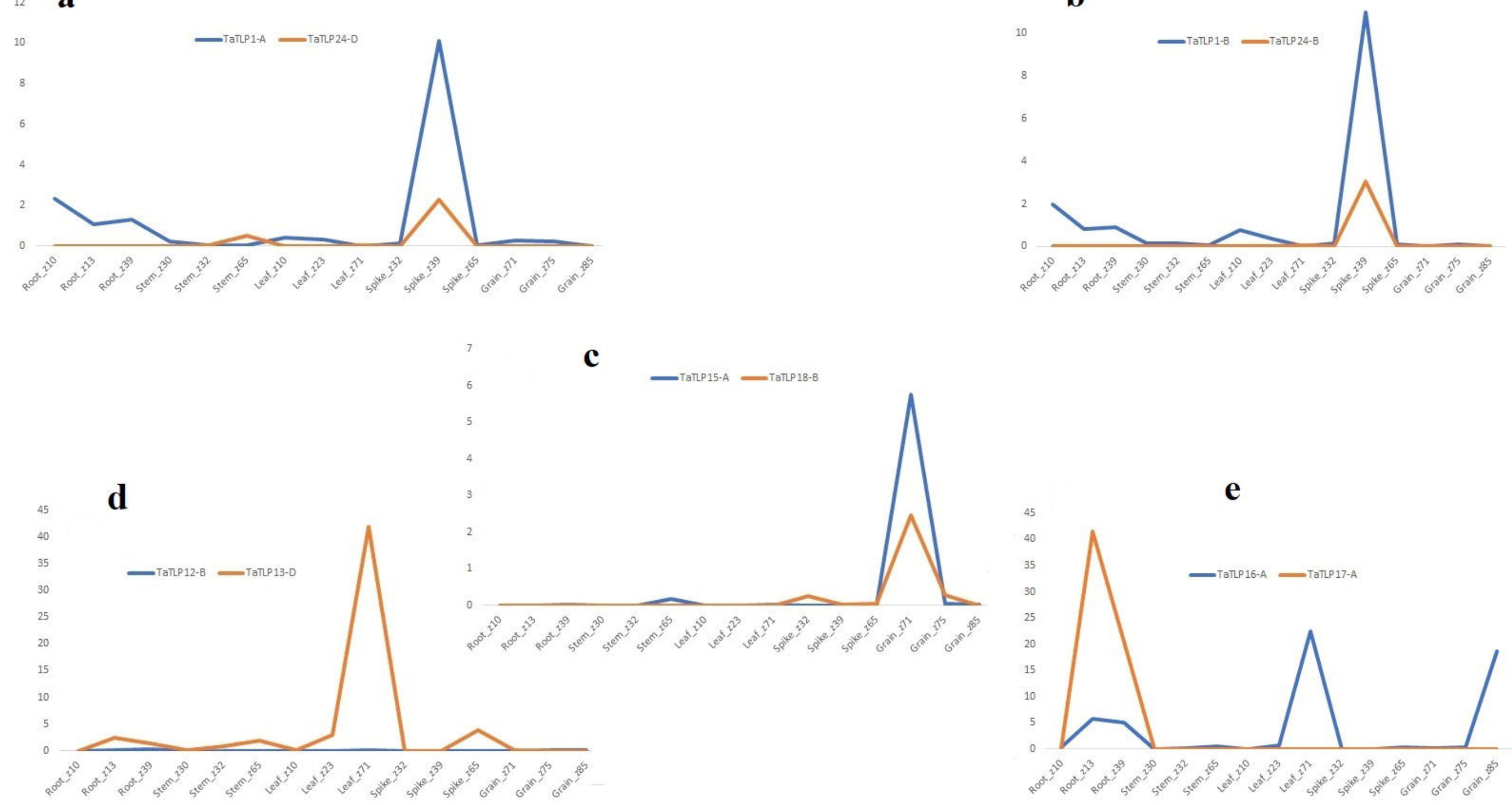